\title{
Effect of graphite nanoplatelets on spark plasma sintered and conventionally sintered aluminum-based nanocomposites developed by powder metallurgy
}

\author{
Pankaj Shrivastava $^{1}$, Syed Nasimul Alam ${ }^{1, *}$, Taraknath Maity ${ }^{2}$, Krishanu Biswas $^{2}$ \\ ${ }^{1}$ Department of Metallurgical and Materials Engineering, National Institute of Technology Rourkela, Odisha 769008, India \\ ${ }^{2}$ Department of Material Science and Engineering, Indian Institute of Technology Kanpur, Uttar Pradesh 208016, India \\ In this work, aluminum (Al)-based nanocomposites reinforced with graphite nanoplatelets (GnPs) have been fabricated \\ by conventional sintering as well as spark plasma sintering (SPS) techniques, and their microstructure and mechanical prop- \\ erties have been studied. The powder metallurgy (PM) route has been adopted to fabricate the various Al-GnP nanocompos- \\ ites. Characterization of the powder mixtures and the nanocomposites has been carried out through different characterization \\ techniques, such as X-ray diffraction (XRD), scanning electron microscopy (SEM), high-resolution transmission electron mi- \\ croscopy (HRTEM), and Raman spectroscopy. Compressive strength, Young's modulus, density, and Vickers microhardness of \\ the various nanocomposites have also been determined. The HRTEM results show the formation of nonstoichiometric $\mathrm{Al}_{4} \mathrm{C}_{3}$ \\ nanoparticles - during both conventional sintering and SPS - at the interface of the Al grains and GnP, which worsen the \\ mechanical properties of the nanocomposites. SPSed nanocomposites show superior mechanical properties due to higher den- \\ sification, finer grain size, and homogeneous nanofiller dispersion in the Al matrix, compared to the conventionally sintered \\ Al-GnP nanocomposites.
}

Keywords: Al-matrix nanocomposites, graphite nanoplatelets, wear, HRTEM, spark plasma sintering

\section{Introduction}

Metals, when reinforced with nanosized carbonaceous materials to form metal-matrix nanocomposites (MMnCs), give excellent mechanical and wear performance in comparison to the performance of their pure forms. Generally, MMnCs show synergistic properties derived from their individual composite constituents, i.e., matrix and reinforcement. From the metal matrix, toughness and required ductility are inherited, and higher strength and other significant properties such as hardness and density, are imparted by the reinforcements [1]. There are several applications of MMnCs as structural materials in areas such as automotive, defense, aerospace, and marine industries. Several metals and alloys of magnesium $(\mathrm{Mg})$, iron $(\mathrm{Fe})$, aluminum $(\mathrm{Al})$, copper $(\mathrm{Cu})$, and nickel (Ni) are extensively used as matrixes to form MMnCs for different industrial applications,

\footnotetext{
*E-mail: nasimulalam@yahoo.com
}

Among all metals, Al is the most widely used matrix due to its superior specific properties, such as low weight, high specific modulus, and so on $[2,3]$. It is very difficult to introduce a carbonaceous nanofiller within the Al metal matrix. The mixing of the Al powder with the carbonaceous nanofiller by the wet mixing method is a very challenging process due to the large difference in surface tension between $\mathrm{Al}(955 \mathrm{mN} / \mathrm{m})$ and the carbonaceous nanofiller $(\sim 45 \mathrm{mN} / \mathrm{m})$ [4]. The dispersion of the nanofiller is a crucial part of the formation of the nanocomposite. The blending of powder, consolidation of powder, and optimized processing parameters for achieving superior properties in the nanocomposites play a crucial part in the development of the nanocomposite. Poor dispersion of the carbonaceous nanofillers could result in deterioration of the performance of the nanocomposite [5].

The development of nanocomposites aims to provide enormous strength to the base matrix. The 
strengthening of $\mathrm{MMnCs}$ by the carbonaceous nanofillers can be attributed to the nanocomposites' outstanding load-bearing ability and stress transfer efficiency. In the nanocomposite, the major load is carried by the reinforcement, and elasticity is provided by the matrix [6]. Graphene - or its derivative few-layer graphene (FLG) shows tremendous load-bearing capacity. Graphite nanoplatelet $(\mathrm{GnP})$ is a derivative of graphite and, compared to graphene, it is comparatively cheaper, is easy to produce, and provides considerable strength. Graphene is an $\mathrm{sp}^{2}$ hybridized twodimensional (2D) allotrope of carbon. When the graphene layers are stacked one over the other, 3D graphite is formed; similarly, when rolled cylindrically, graphene forms 1D nanotubes and, when wrapped, it forms 0D fullerenes [7, 8]. Graphene has attracted remarkable research interests globally owing to its 2D structure and unit atomic thickness, which provides it with exceptional physical properties. It has a density of $2.26 \mathrm{~g} / \mathrm{cm}^{3}$, thermal conductivity of $5,000 \mathrm{Wm} / \mathrm{K}$, and a surface area of $2,600 \mathrm{~m}^{2} / \mathrm{g}$. In addition, graphene provides extraordinary fractural strength of $\sim 125 \mathrm{GPa}$ and elastic modulus $\sim 1 \mathrm{TPa}$ [9-11].

A lot of work has already been done by various researchers on using graphene and its derivatives for reinforcing the Al metal matrix. Nanofillers such as graphene and its different derivatives, carbon nanotubes (CNTs) and other carbonaceous nanofillers, have attracted researchers from different fields to fabricate composites due to their exceptional and comparatively superior properties [12-14]. Recent studies show that graphemereinforced Al-matrix nanocomposites exhibit exceptional mechanical and physical properties in the fields of automotive and energy sectors, biomedical and implants industries, etc., which make them promising future materials [15-18]. Rashad et al. [11] developed Al-matrix composites reinforced with GnPs by a semi-powder metallurgy (semiPM) technique and reported that even a small amount of $\mathrm{GnP}(0.3$ wt.\%) has the potential to enhance the mechanical properties, such as tensile strength, by $11.1 \%$ with respect to the unreinforced monolithic Al. A small amount of graphene (0.1 wt.\%) was also added by Bartolucci et al. [19] in the development of Al-matrix composites using the ball-milling blending technique, followed by hot isostatic pressing at $550^{\circ} \mathrm{C}$ and extrusion. However, an enhancement in the mechanical properties was observed along with the formation of detrimental $\mathrm{Al}_{4} \mathrm{C}_{3}$ due to the prolonged ball milling and high-temperature sintering. Ju et al. [20] also fabricated graphene-reinforced Al-matrix composites having $0.3 \mathrm{wt} . \%$ graphene content with varying $\mathrm{Mg}^{2+}$ content through the spark plasma sintering (SPS) process. $\mathrm{Mg}^{2+}$ ions were used as binding bridges that anchored graphene sheests to the surface of Al powder. Dispersion was found to have improved due to the facile process adopted. SPS and dispersion of graphene resulted in significant improvement in the compressive strength of the synthesized composites. Dutkiewicz et al. [21] fabricated graphene-reinforced $\mathrm{Cu}$-based composites via ball milling, followed by hot pressing. It was observed that a smaller size of graphene had a better effect in enhancing the properties, compared to larger-sized graphene, as the latter tended to agglomerate to a greater extent and easily. It was also found that milling and hot pressing were time-consuming and costly processes. In addition, ball milling was found to be detrimental to the graphene plates, hence increasing the defects. On the other hand, SPS is a quick, low-temperatureassisted high-quality technique for the synthesis of graphene-based composites [22, 23]. However, limited studies are available for graphenereinforced metal-matrix composites (MMCs) developed by the SPS and PM techniques. Moreover, there is still a gap with respect to the characterization and property investigation of SPSed Al-matrix nanocomposites, along with a comparative analysis between the conventionally sintered and SPSed nanocomposites, and the present work tries to bridge this gap. Al powder and GnPs were blended in an acetone bath using ultrasonication, and the sintered composites were tested to understand the effect of GnPs. For the fabrication of Al-based nanocomposites using carbonaceous nanofillers, the PM route is widely used. The PM route has its benefits relative to casting and other manufacturing processes as a homogeneous dispersion of the reinforcement is possible by this 


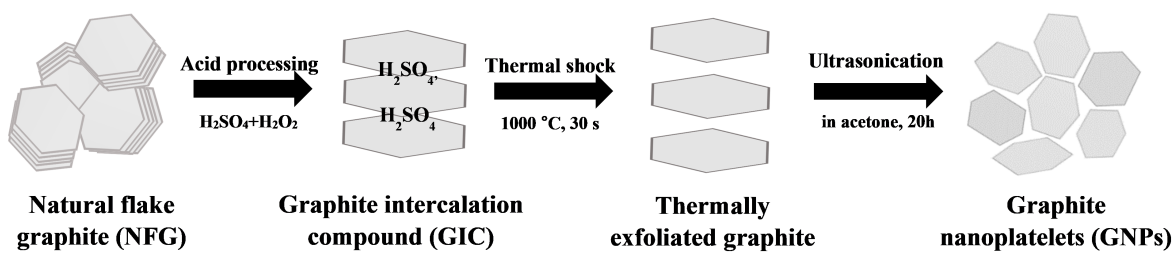

Fig. 1. Synthesis of GnPs from NFG. GIC, graphite intercalation compound; GnP, graphite nanoplatelet; NFG, natural flake graphite.

technique. This study aims to fabricate Al-GnP nanocomposites by the PM route, followed by sintering of the samples by conventional sintering and SPS techniques. The characterization and investigations of the mechanical property of the various $\mathrm{Al}-\mathrm{GnP}$ nanocomposites have been conducted.

\section{Experimental}

\subsection{Synthesis of GnPs}

The schematic diagram given in Figure 1 depicts the process of synthesis of GnPs from natural flake graphite (NFG). NFG having a purity of $>99 \%$ was procured from Loba Chemie, Mumbai, Maharashtra, India. Initially, the NFG is intercalated with acids to form the graphite intercalation compound (GIC) by adding $19 \mathrm{ml}$ of concentrated $\mathrm{H}_{2} \mathrm{SO}_{4}$ and $8 \mathrm{ml}$ of $\mathrm{H}_{2} \mathrm{O}_{2}(30 \%)$ to about $6 \mathrm{~g}$ of NFG. The GIC is then stirred magnetically intermittently for a total of $4 \mathrm{~h}$. The obtained semifoamed mixture is treated several times in a funneland-filter setup with distilled water to remove the unwanted acids until it attains a near-neutral $\mathrm{pH}$ value, followed by overnight air-drying and later complete drying in an oven overnight for $8 \mathrm{~h}$ at $80^{\circ} \mathrm{C}$ [24]. The agglomerates formed after furnace drying are ground to a fine powder using a pestle and mortar. Now, at $1,000^{\circ} \mathrm{C}$, a thermal shock is provided for $30 \mathrm{~s}$ to the finely powdered GIC. This yields thermally exfoliated graphite, which is later ultrasonicated for $20 \mathrm{~h}$ intermittently to obtain the GnPs. After long ultrasonic treatment, a stable dispersion of GnPs having FLG is formed in the acetone medium. The platelet morphology of the GnPs is highly effective in providing the barrier property that improves the mechanical properties of nanocomposites.

\subsection{Fabrication of composites}

The Al-GnP powder mixture was synthesized by an ultrasonication process. Pure Al powder having a purity of $>99.7 \%$ was procured from Loba Chemie. The Al-GnP blended powder mixture in a powder-to-acetone ratio of 1:50 was ultrasonicated for $4 \mathrm{~h}$ intermittently. Acetone is a suitable solvent for ultrasonication as it helps in deagglomerating the mixture, and it does not participate in the process. The mixture obtained after ultrasonication was oven-dried for $1 \mathrm{~d}$ at $80^{\circ} \mathrm{C}$. Homogeneous powder mixtures of $\mathrm{Al}-x$ wt. $\% \mathrm{GnPs}$ (where $x=1,2,3,4$, and 5) were prepared by the above process. The blended powder mixtures along with pure Al powder were then compacted under a load of $500 \mathrm{MPa}$ for a dwell time of $5 \mathrm{~min}$ using a uniaxial hydraulic compaction machine. The green compacts were conventionally sintered in an Ar atmosphere at $550^{\circ} \mathrm{C}$ for a dwell time of $2 \mathrm{~h}$ in a tubular furnace manufactured by Bysakh and Company, Kolkata, West Bengal, India. SPS of pure Al and Al-1 wt.\%, 3 wt.\%, and 5 wt.\% GnPs was also done for comparative analysis. The blended powders were fed in a spark-assisted Dr. Sinter 515S SPS tool (SPS Syntex Inc., Kanagawa, Japan) between electrically conducting graphite dies, and sintering was performed at $500^{\circ} \mathrm{C}$ for $10 \mathrm{~min}$ under a load of $50 \mathrm{MPa}$. All the sintered samples were later polished and characterized using various techniques.

\subsection{Characterization of composites}

A Rigaku Ultima IV diffractometer was used for X-ray diffraction (XRD) of various powder and sintered samples using $\mathrm{Cu} \mathrm{K}_{\alpha}(\lambda=1.542 \AA)$ target. A Jeol JSM 6480LV scanning electron microscope with a field emission bulb was used 
for scanning electron microscopy (SEM) and an FEI Nova NanoSEM-450 was used for field emission gun-assisted SEM (FESEM) to obtain the micrographs of the powder and sintered samples. High-resolution transmission electron microscopy (HRTEM) was used for microstructural analysis of the various powders and sintered samples using an FEI Tecnai G2 TF30-ST instrument. A WITec Model-XMB3000-3000 Raman spectroscope was used with a $532 \mathrm{~nm}$ laser to detect the intensities of defects in the synthesized GnPs. A Carl Zeiss Axio Vert. An A1 light microscope was used to obtain the micrographs of etched sintered samples. Keller's reagent, containing distilled $\mathrm{H}_{2} \mathrm{O}(190 \mathrm{ml})$ and the highly concentrated $(98 \%)$ acids $\mathrm{HNO}_{3}$ $(5 \mathrm{ml}), \mathrm{HCl}(3 \mathrm{ml})$, and $\mathrm{HF}(2 \mathrm{ml})$, was used as the etchant. The polished sintered samples were exposed to the freshly prepared etchant for 10-30 s [25]. The experimental densities and porosities of the sintered samples were determined by following Archimedes' principle. A Contech model-CB300 density measuring kit was used to determine the weights of the different samples using distilled water $\left(\rho=1 \mathrm{~g} / \mathrm{cm}^{3}\right)$ as the reference liquid. The reference densities of pure $\mathrm{Al}$ and the GnPs were considered as $2.7 \mathrm{~g} / \mathrm{cm}^{3}$ and $2.26 \mathrm{~g} / \mathrm{cm}^{3}$, respectively [26]. A Leco LM248AT Vickers microhardness tester having a pyramidal diamond indenter was used to determine the hardness of the sintered samples with an indent load of $10 \mathrm{gf}$ and a dwell time of $10 \mathrm{~s}$. The specimens for the compression test were prepared according to American Society for Testing and Materials (ASTM) E9 standards. Short cylindrical specimens having a diameter of $15 \mathrm{~mm}$ and length of $15 \pm 1 \mathrm{~mm}$ were prepared, and the compressive test was performed in an Instron 8862 Digital Servo-Electric universal testing machine at a constant slow strain rate of $0.5 \mathrm{~mm} / \mathrm{min}$. The tests were carried out until the initiation of crack in the sample. Wear test of the various samples was performed using a DUCOM TR208-M1 tribometer with SAE 52100 steel ball indenter having a diameter of $2 \mathrm{~mm}$. The wear tests were performed under a load of $15 \mathrm{~N}$ with a rotational speed of $20 \mathrm{rev} / \mathrm{min}$ for $10 \mathrm{~min}$.

\section{Results and discussion}

The XRD plot of GnPs, along with the inprocess constituents, is depicted in Figure 2(A). Figure 2(B) shows the (002) diffraction peak of $\mathrm{GnPs}$ and other constituents at $2 \theta=26.5^{\circ}$. The XRD plots of NFG, GIC, thermally exfoliated graphite, and $\mathrm{GnP}$ indicates the stepwise formation of GnP. Initially, NFG is processed to form GIC, followed by its thermal exfoliation and subsequent sonication in acetone medium. The GnP formed shows the highest intensity of the (002) peak, indicating its high degree of crystallinity and suggesting that the $\mathrm{GnP}$ is made up of a few layers of

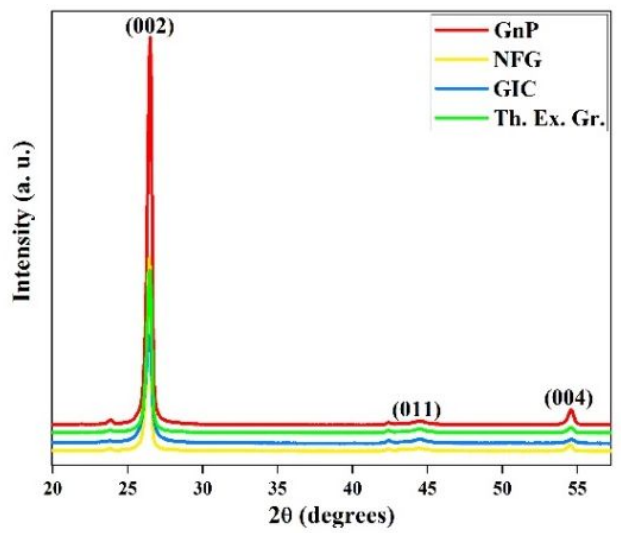

(a)

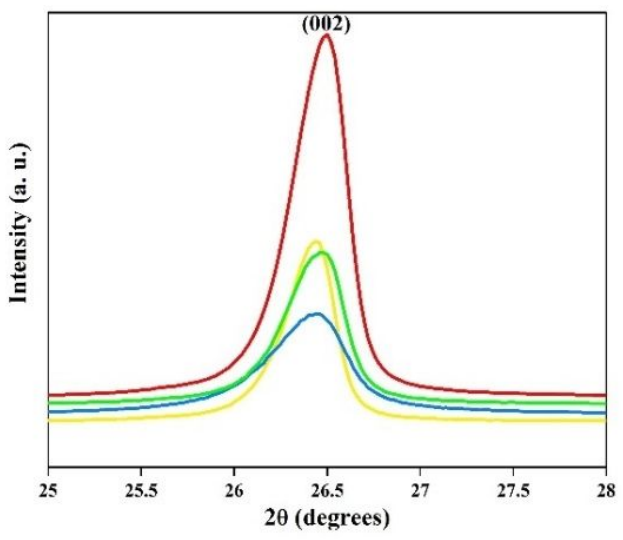

(b)

Fig. 2. (A) XRD and (B) (002) peak of NFG, GIC, thermally exfoliated graphite, and GnP. a.u., arbitrary unit; GIC, graphite intercalation compound; GnP, graphite nanoplatelet; NFG, natural flake graphite; Th. Ex. Gr., thermally exfoliated graphite; XRD, X-ray diffraction. 


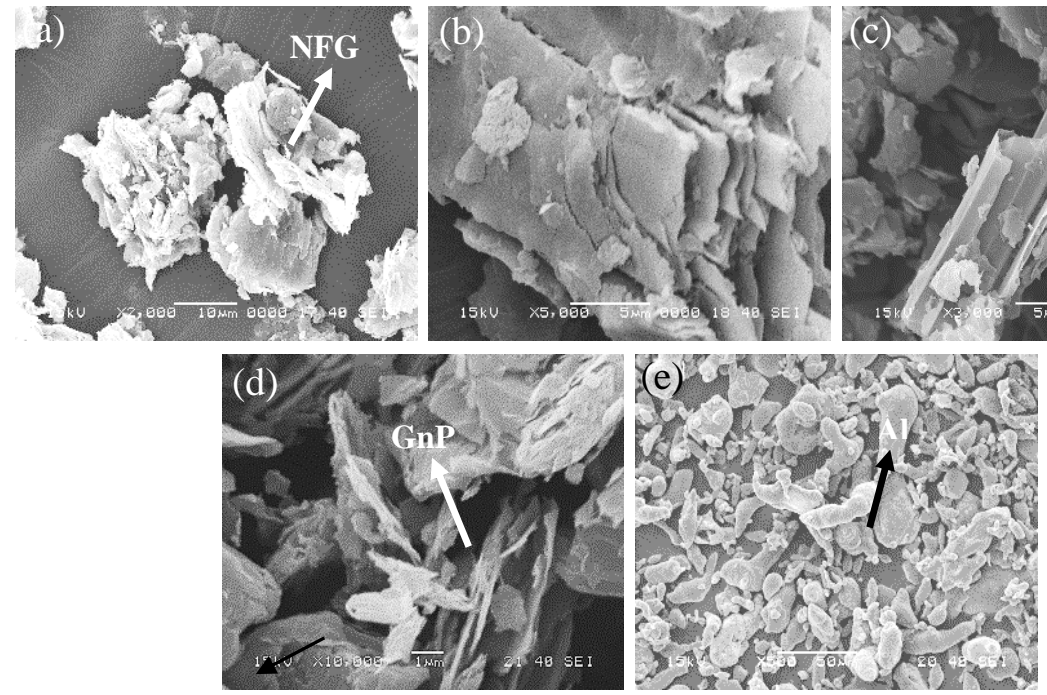

Fig. 3. SEM images of (A) NFG (B) GIC, (C) thermally exfoliated graphite, (D) GnPs, and (E) pure Al. GIC, graphite intercalation compound; GnPs, graphite nanoplatelets; NFG, natural flake graphite; SEM, scanning electron microscopy.
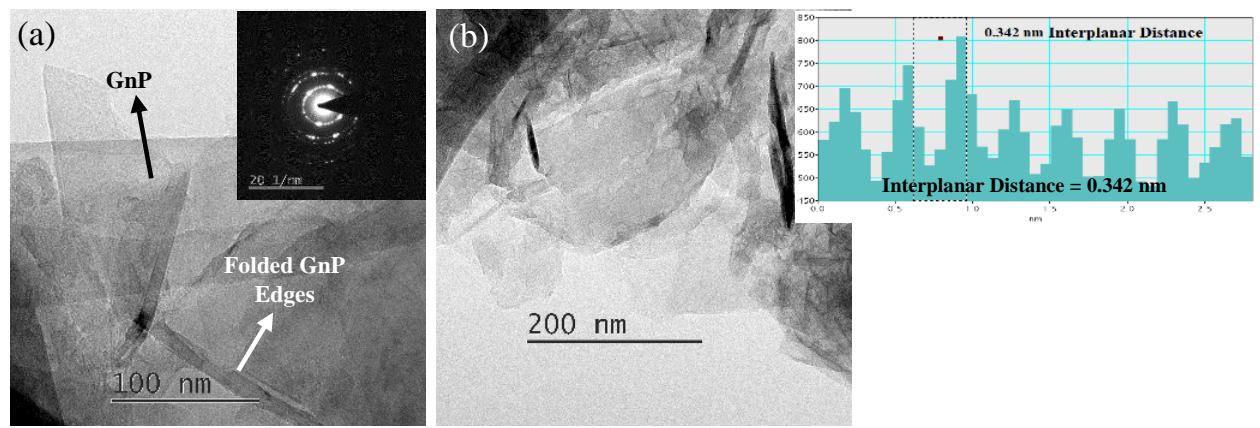

Fig. 4. HRTEM images of GnP powder. GnP, graphite nanoplatelet; HRTEM, high-resolution transmission electron microscopy.

pristine graphene [27]. The $\mathrm{d}_{002}$ spacing of pristine graphene has been reported to be $3.37 \AA$ and the $\mathrm{d}_{002}$ of the GnP synthesized here is $3.34 \AA$, which is very close to that of pristine graphene $[28,29]$.

Figure 3(A) shows the SEM micrograph of the NFG that was used for the synthesis of GnP. The NFG is intercalated with $\mathrm{H}_{2} \mathrm{SO}_{4}$ and $\mathrm{H}_{2} \mathrm{O}_{2}$ to form a foamy product known as the GIC, shown in the SEM micrograph in Figure 3(B). The GIC is given a thermal shock at $1,000^{\circ} \mathrm{C}$ for $30 \mathrm{~s}$ to completely evaporate the intercalated acid without damaging the GnPs. Figure 3(C) shows the thermally exfoliated graphite obtained after thermal shock. The thermally treated GIC is now ultrasonicated for
$20 \mathrm{~h}$ intermittently to obtain the exfoliated GnPs shown in Figure 3(D). The 2D plate-like structure of the GnPs containing a few layers of graphene is evident from the SEM micrograph. Figure 3(E) shows the dumbbell morphology of the as-received Al powder having a particle size ranging within 20$50 \mu \mathrm{m}$. The Al powder is blended with GnPs by ultrasonication in the desired weight ratio to form the various $\mathrm{Al}-\mathrm{GnP}$ powder mixtures.

Figure 4(A) is the HRTEM image of the GnPs, along with the selected area electron diffraction (SAED) pattern inset. It can be seen from the HRTEM image that the synthesized GnPs have very few overlapped graphene layers. Folding of 
the GnPs can be seen at the edges. Few agglomerates of GnPs can also be seen, along with wrinkles and entangled edges due to the bending of the GnPs, in Figure 4(B). The SAED pattern inset shows sharp diffraction rings, indicating the high crystallinity of the GnP. It shows the six-fold symmetry of the hexagonal structure of carbon and suggests that the structure of the GnPs is preserved during the synthesis process $[30,31]$. Prolonged ultrasonication for $20 \mathrm{~h}$ increased the extent of exfoliation and resulted in electron-transparent GnPs having few layers of graphene. Highly crystalline and pristine graphene is known to be transparent to electron beams $[32,33]$.

Figure 5 shows the Raman spectra of the synthesized GnP powder. Raman spectroscopy is a vibrational technique that is extremely sensitive to the geometric structure and bonding within the molecules; it can determine the layer thickness at atomic layer resolution and distinguish monolayer graphene from FLG. It can determine disorder and functional groups and give an idea of the quality of the carbonaceous nanomaterials. It gives us information on the basic properties such as impurities, crystallinity, structural damages, number of layers present, disorder, and factors associated with the defects $[34,35]$. The shifting in the $\mathrm{D}$ and the $2 \mathrm{D}$ peaks is related to the increase in the number of graphene layers stacked in the GnPs. The Dband shows the existence of a disordered molecular structure, whereas the G-band indicates the inplane vibrations of the $\mathrm{sp}^{2}$ carbon bond. The Dband becomes active only in the presence of defects and is not present in perfect single-crystal graphite. The D-band originates from a hybridized vibrational mode associated with graphene edges, and it indicates the presence of some disorder in the graphite structure. The D-band is the dominant $\mathrm{sp}^{2}$ Raman signature of disorder or defects. The 2Dband strongly depends on the frequency of exciting laser energy and gives structural information about graphene. For materials such as graphene, the dominant vibration mode lies around three wavenumbers. As can be seen in Figure 5, the D-band at $\sim 1,349 / \mathrm{cm}$ specifies the existence of imperfection, disorder in the lattice, and defects in the GnPs. The higher the extent of defect in the GnPs, the higher is the intensity of the D-band. This indicates the presence of $\mathrm{sp}^{3}$ bonds in the GnPs. Using the intensity ratio of D-band to G-band $\left(I_{D} / I_{G}\right)$, it is possible to characterize the level of disorder in graphene. The $I_{D} / I_{G}$ ratio is largely used to measure the amount of disorder. An increase in the $I_{D} / I_{G}$ ratio is ascribed to an increase in the number and size of $\mathrm{sp}^{2}$ clusters. The lesser the $I_{D} / I_{G}$ ratio, the more ordered the structure will be [36]. A very low $I_{D} / I_{G}$ ratio of $\sim 0.68$ for the GnP sample synthesized by the technique discussed above suggests the presence of very few defects and the establishment of a well-ordered crystal structure of the GnPs. The Gband located at $\sim 1,585 / \mathrm{cm}$ is due to the $\mathrm{C}-\mathrm{C}$ bond stretching present in the carbonaceous materials that escaped from the carbon bonding E2g vibrational mode. The 2D-band located at $\sim 2,700 / \mathrm{cm}$ is the reflection of the structure of their $\pi$-electron zones. The nature of the 2D band, its frequency, and its intensity are greatly influenced by the number of stacked graphene layers. Its intensity is large in the case of single-layer graphene and reduces in the case of multilayer graphene. From the 2D band in the Raman spectrum in Figure 5, it is evident that the GnPs synthesized herein have a few layers of graphene stacked together.

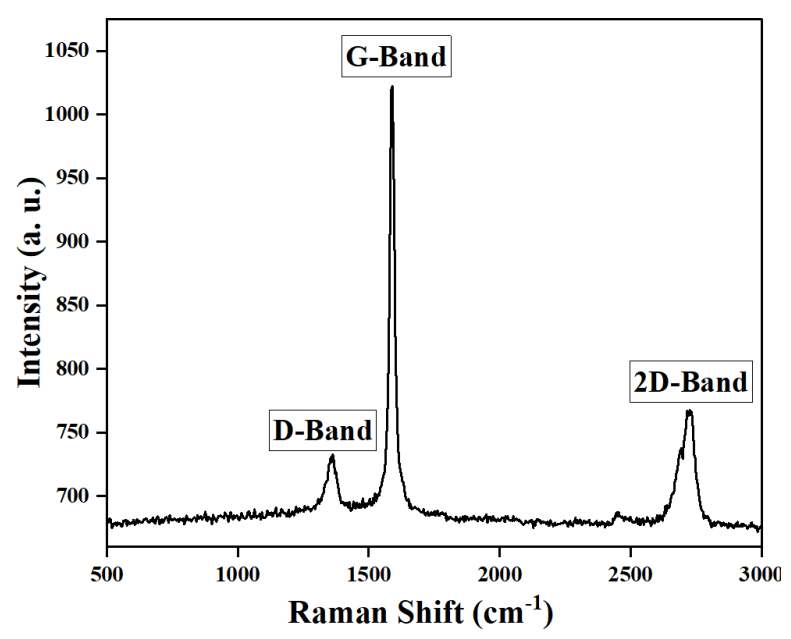

Fig. 5. Raman spectra of GnPs. a.u., arbitrary unit; GnP, graphite nanoplatelet.

Figure 6 shows the SEM micrographs of various Al-GnP powder mixtures. Figure 6(A-D) shows that when $\mathrm{GnP}$ addition is increased gradually from 

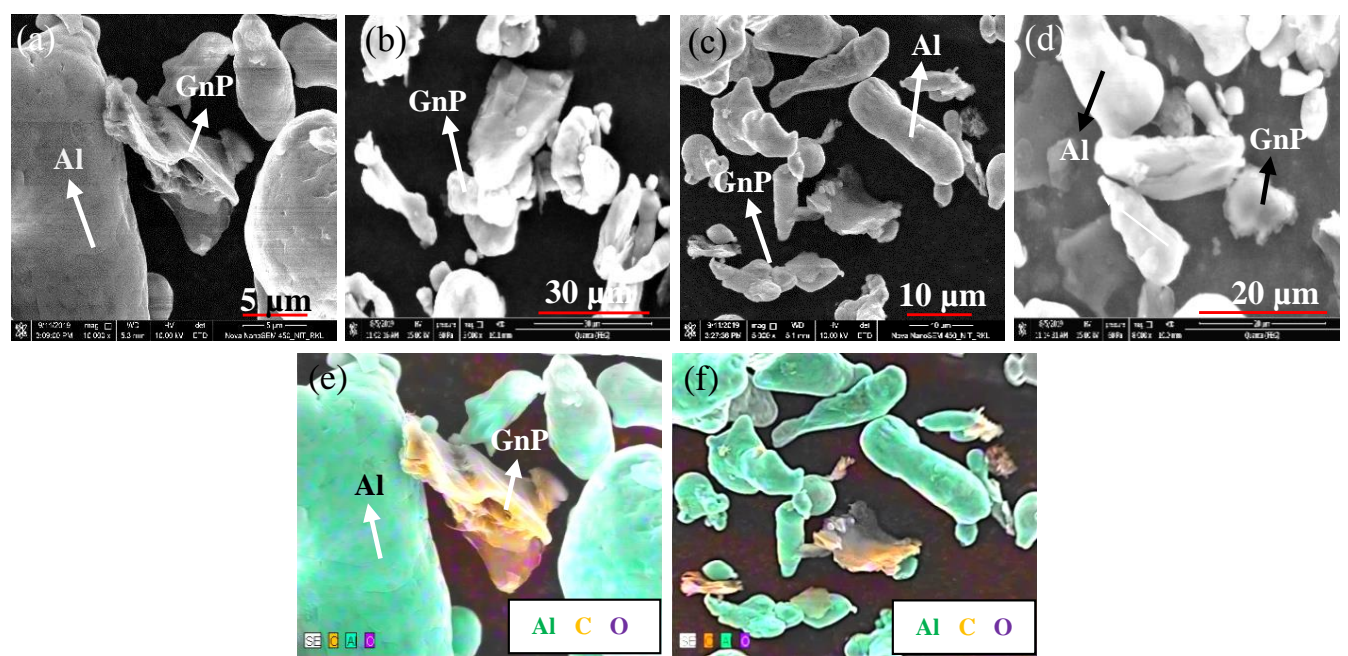

Fig. 6. (A-D) SEM micrographs of Al-1 wt.\% to Al-5 wt.\% GnP powder mixtures and elemental mapping of (E) 1 wt.\% and (F) 3 wt.\% GnPs added to Al powder. GnP, graphite nanoplatelet; SEM, scanning electron microscopy.
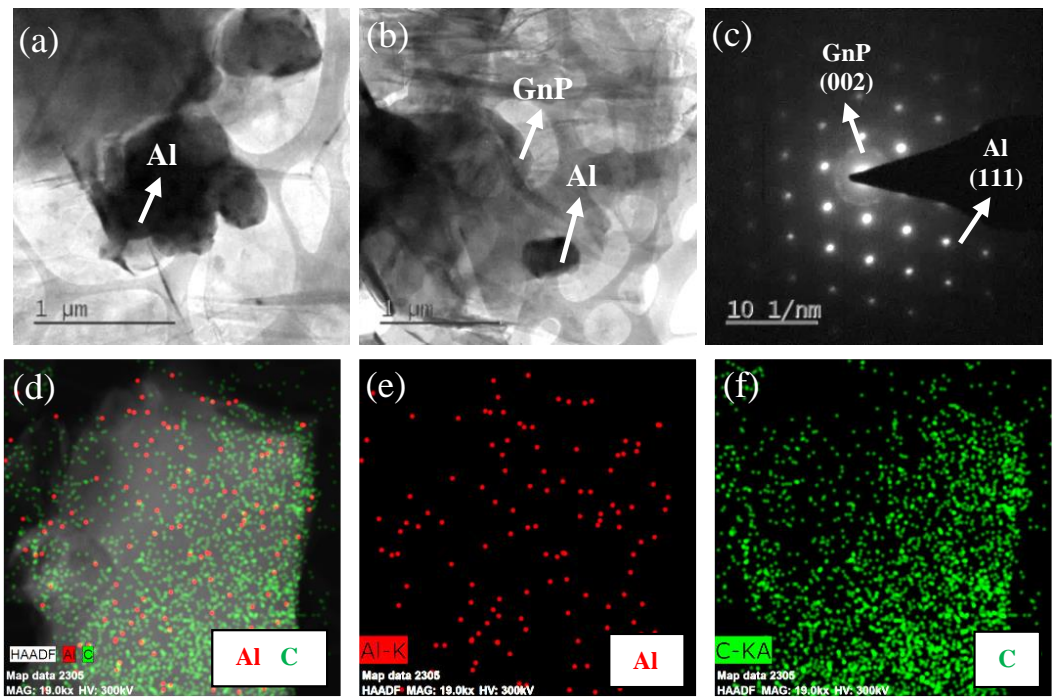

Fig. 7. (A, B) HRTEM micrographs, (C) SAED pattern, and (D-F) elemental maps of Al-2 wt.\% GnP powder mixture. GnP, graphite nanoplatelet; HRTEM, high-resolution transmission electron microscopy.

$1 \mathrm{wt} . \%$ to $5 \mathrm{wt} . \%$, an increase is observed in the contact between the Al particles and the GnPs. Ultrasonication of the Al powder with the GnPs results in uniform distribution of the GnPs in the $\mathrm{Al}$ powder. Figure 6(E and F) shows the elemental maps of Al-1 wt.\% and 3 wt.\% GnP powder mixtures. The mapping clearly shows the distributed $\mathrm{GnPs}$ within the $\mathrm{Al}$ matrix and the association of the Al particles with the GnP $[37,38]$.
Figure 7 shows the HRTEM micrographs of a blended powder of 2 wt.\% GnPs added in the Al matrix. The HRTEM micrographs indicate the presence of very thin, flake-like GnPs surrounding the Al particles. Here, low-magnification images have been shown to indicate the overall feature of the Al-GnP powder mixture. Figure 7(C) shows the SAED pattern, which confirms the presence of both the blended constituents. The hexag- 
onal spot pattern confirms the undamaged highly crystalline GnP structure and the surrounding linear spot pattern shows the presence of $\mathrm{Al}$ particles in the blended powder mixture. It has been reported that graphene properties are very subtle to lattice defects and both intrinsic and extrinsic disorders $[39,40]$. The elemental maps in Figure 7(DF) show the uniform dispersion of GnPs within the Al particles.

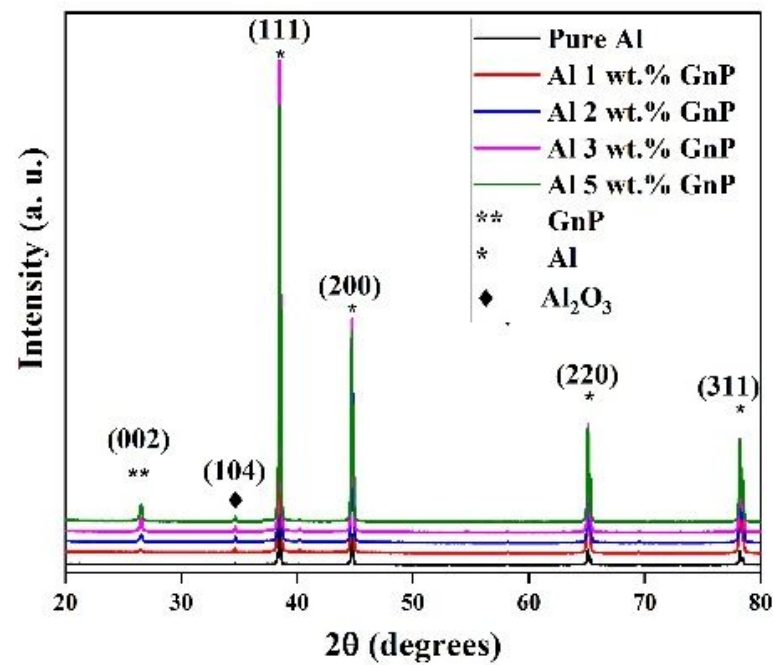

(a)

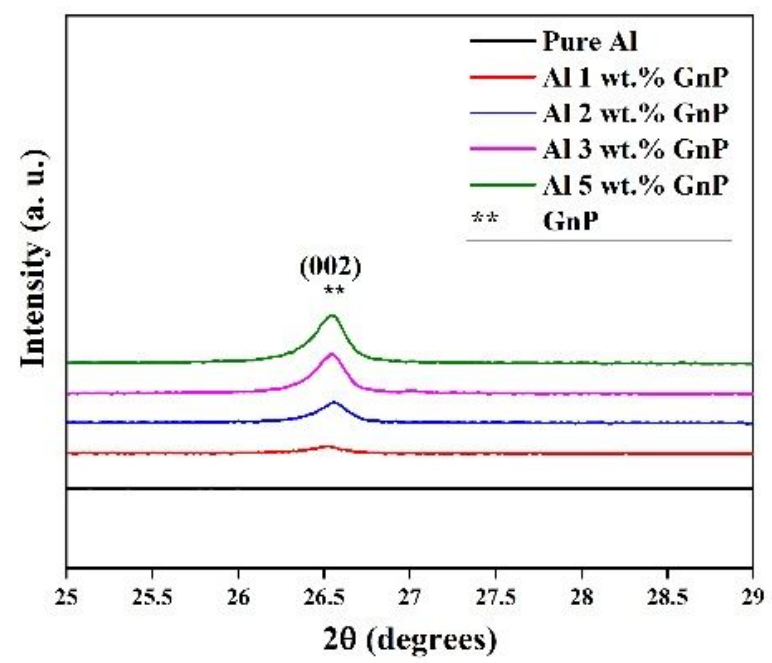

(b)

Fig. 8. (A) XRD plots of pure $\mathrm{Al}$ and various $\mathrm{Al}-\mathrm{GnP}$ powder mixtures; (B) (002) peaks of GnPs. a.u., arbitrary unit; GnP, graphite nanoplatelet; XRD, $\mathrm{X}$-ray diffraction.
Figure $8(\mathrm{~A})$ shows the XRD plots of pure $\mathrm{Al}$ and the various $\mathrm{Al}-\mathrm{GnP}$ powder mixtures in the $2 \theta$ range of $20^{\circ}-80^{\circ}$. All the XRD plots show peaks corresponding to (111), (200), (220), and (311) planes of face-centered cubic Al metal. The (002) peak at $2 \theta$ value of $\sim 26.5$ confirms the presence of GnPs in the blended mixture, and it intensifies with an increase in its loading level [Figure 8(B)]. A very-low-intensity (104) peak corresponding to aluminum oxide $\left(\mathrm{Al}_{2} \mathrm{O}_{3}\right)$ is also seen in the XRD

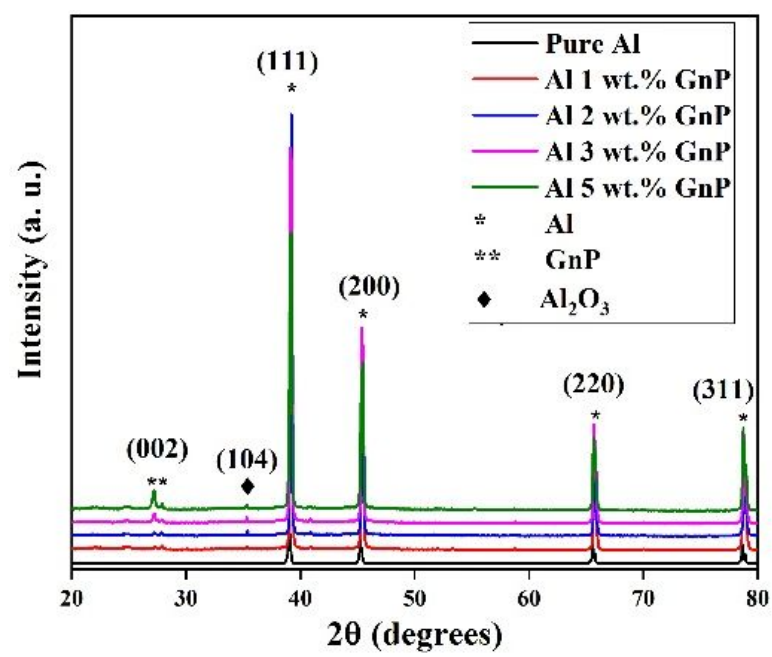

(a)

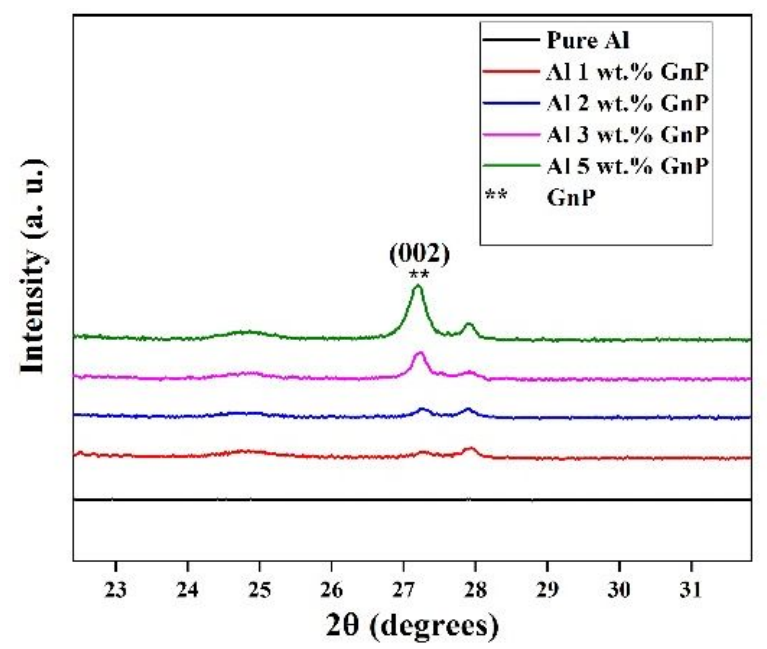

(b)

Fig. 9. (A) XRD plots of various Al-GnP conventionally sintered nanocomposites (B) (002) peaks of GnPs. a.u., arbitrary unit; GnP, graphite nanoplatelet; XRD, X-ray diffraction. 


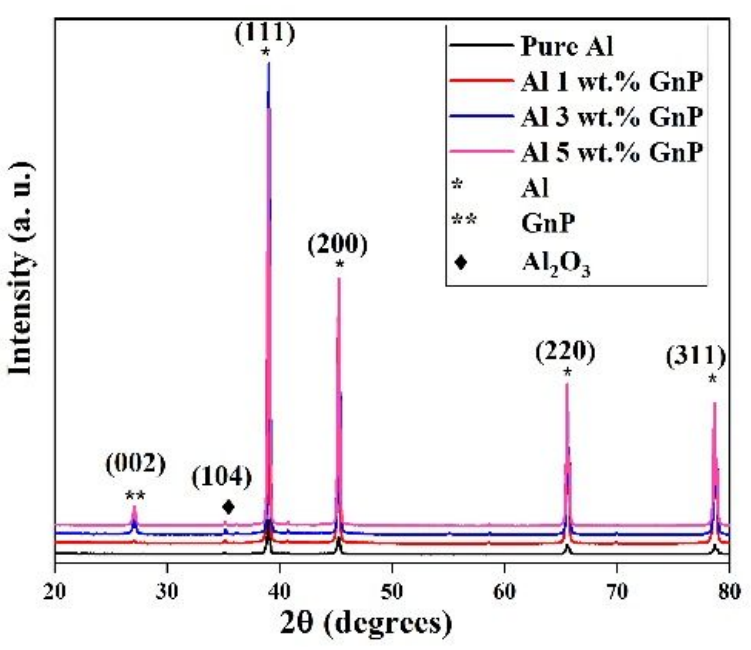

(a)

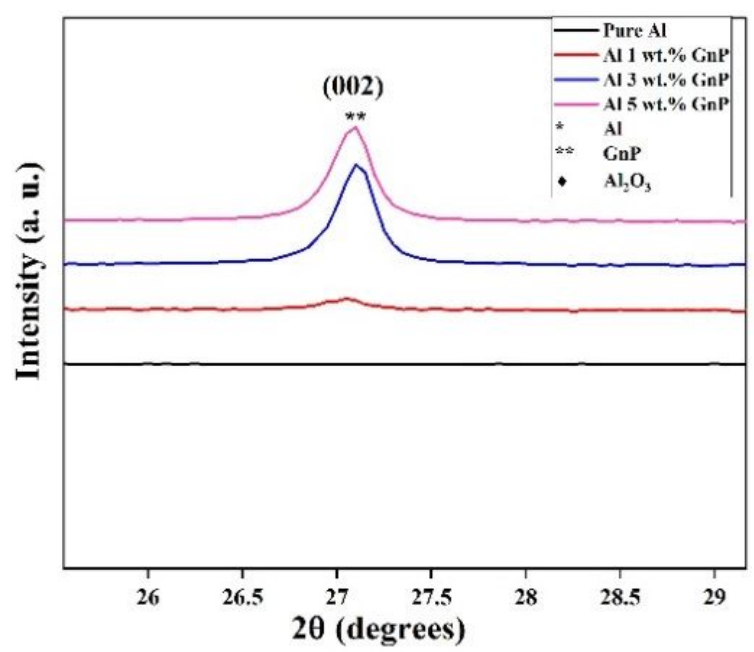

(b)

Fig. 10. (A) XRD plots of various Al-GnP SPSed nanocomposites; (B) (002) peaks of GnPs. a.u., arbitrary unit; GnP, graphite nanoplatelet; SPS, spark plasma sintering; XRD, x-ray diffraction.

plots. $\mathrm{Al}_{2} \mathrm{O}_{3}$ is formed in the blended powder during the oven-drying of the mixture in the air atmosphere.

Figure 9(A) depicts the XRD plot of pure $\mathrm{Al}$ and various conventionally sintered $\mathrm{Al}-\mathrm{GnP}$ nanocomposites. No new peaks of the oxides of $\mathrm{Al}$ are detected in the XRD analysis. This can be attributed to the negligible oxide formation during the sintering process. XRD peaks corresponding to $\mathrm{Al}_{2} \mathrm{O}_{3}$ show very low intensity, suggesting the for- mation of $\mathrm{Al}_{2} \mathrm{O}_{3}$ probably due to the oxide present in the blend and oxygen present in the Ar in the sintering chamber. It can be noticed from Figure 9(B) that when increasing the loading level of $\mathrm{GnP}$ from $1 \mathrm{wt} . \%$ to $5 \mathrm{wt} \%$, the (002) peak corresponding to the GnP reinforcement intensifies and becomes stronger [41, 42].

The XRD analysis of SPSed pure Al and various $\mathrm{Al}-\mathrm{GnP}$ nanocomposites is depicted in Figure 10(A). Figure 10(B and C) shows the variation in intensity of the (002) peak of GnPs and the (111) peak of $\mathrm{Al}$ in the sintered nanocomposite with an increase in the loading level of GnPs. The XRD plots in Figure 10(A) also show very faint peaks corresponding to $\mathrm{Al}_{2} \mathrm{O}_{3}$. It should be noted that although sintering was done in an Ar atmosphere, $\mathrm{Al}_{2} \mathrm{O}_{3}$ was formed due to the oxidation of $\mathrm{Al}$ by residual oxygen present during sintering.

Figure 11 depicts the SEM micrographs and corresponding elemental maps of various pure $\mathrm{Al}$ and conventionally sintered $\mathrm{Al}-\mathrm{GnP}$ nanocomposites. The sintering of $\mathrm{Al}$ has been done below the melting point of $\mathrm{Al}$ (melting point $=660.3^{\circ} \mathrm{C}$ ); therefore, solid state sintering is expected to take place between the Al particles. The SEM micrograph shows the agglomeration of GnP nanofiller within the Al matrix, which continuously increases with a higher loading of the nanofiller. A homogeneous $\mathrm{GnP}$ distribution is evident from the Al-1 wt.\% GnP and Al-2 wt.\% GnP SEM micrographs depicted in Figure 11(B and C), which results in the significant improvement of the strength of the nanocomposite. Later, when nanofiller is added beyond $2 \mathrm{wt} . \%$, the agglomeration of the GnP starts, and with the addition of 5 wt.\% GnPs, it can be seen from the low-magnification SEM image in Figure 11(E) that plenty of agglomerates have formed, which are detrimental to the properties of the nanocomposite. Figure $11(\mathrm{~F}-\mathrm{H})$ shows the elemental mapping of 1 wt. $\%, 2$ wt. $\%$, and 3 wt. $\%$ GnP-added SPSed Al nanocomposites. When the loading level of $\mathrm{GnP}$ is increased from $1 \mathrm{wt} . \%$ to 3 wt.\%, larger agglomerates of GnPs start to form. Homogeneous nanofiller dispersion within the matrix corresponds to superior mechanical properties [43-45].

Figure 12 depicts the SEM micrographs of 

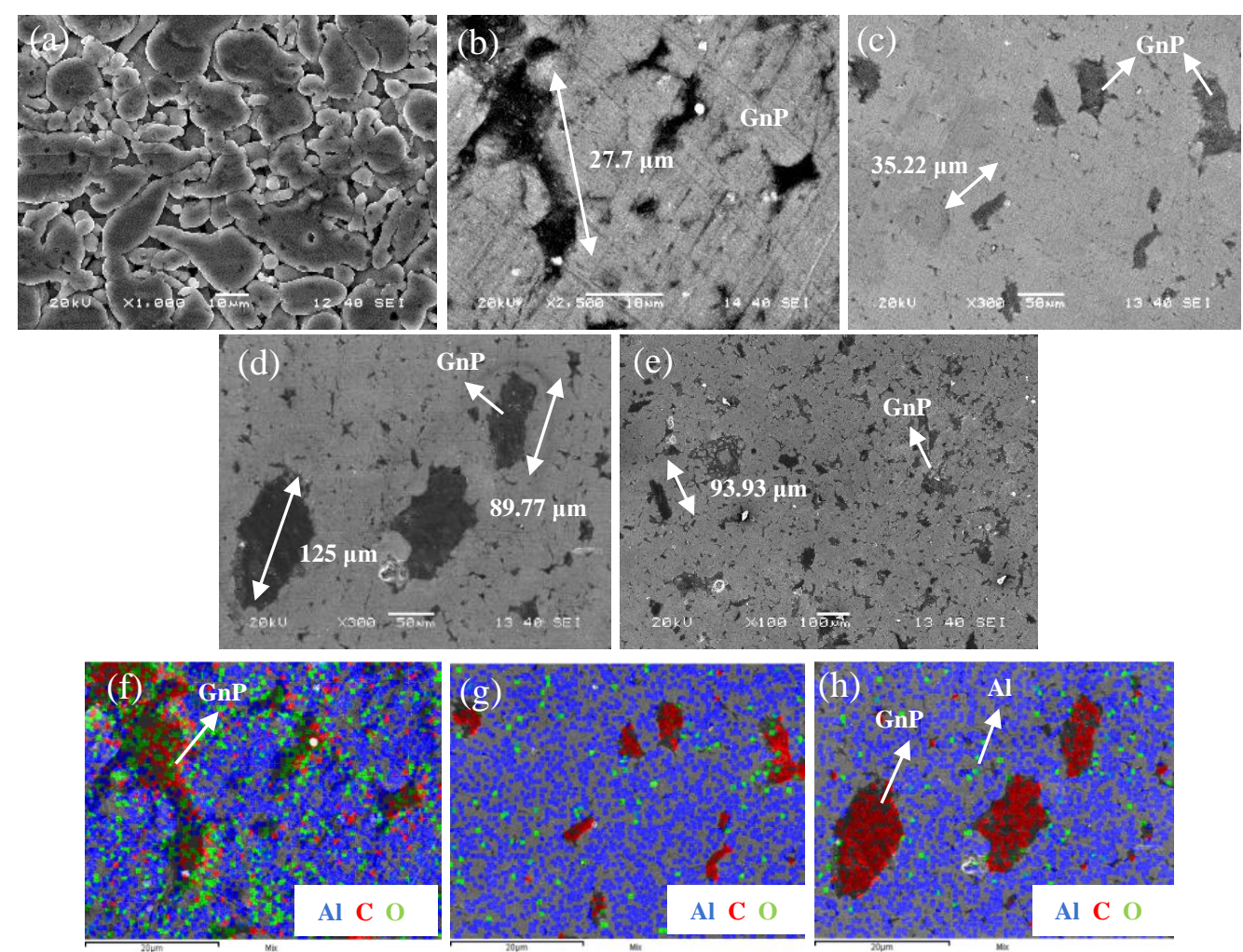

Fig. 11. (A-E) SEM micrographs of conventionally sintered pure $\mathrm{Al}$ and $\mathrm{Al}-1$ wt. $\%, 2$ wt. $\%, 3$ wt. $\%$, and 5 wt.\% GnP nanocomposites; (F-H) elemental maps of Al-1 wt.\%, 2 wt.\%, and 3 wt.\% conventionally sintered $\mathrm{GnP}$ nanocomposites. GnP, graphite nanoplatelet; SEM, scanning electron microscopy.
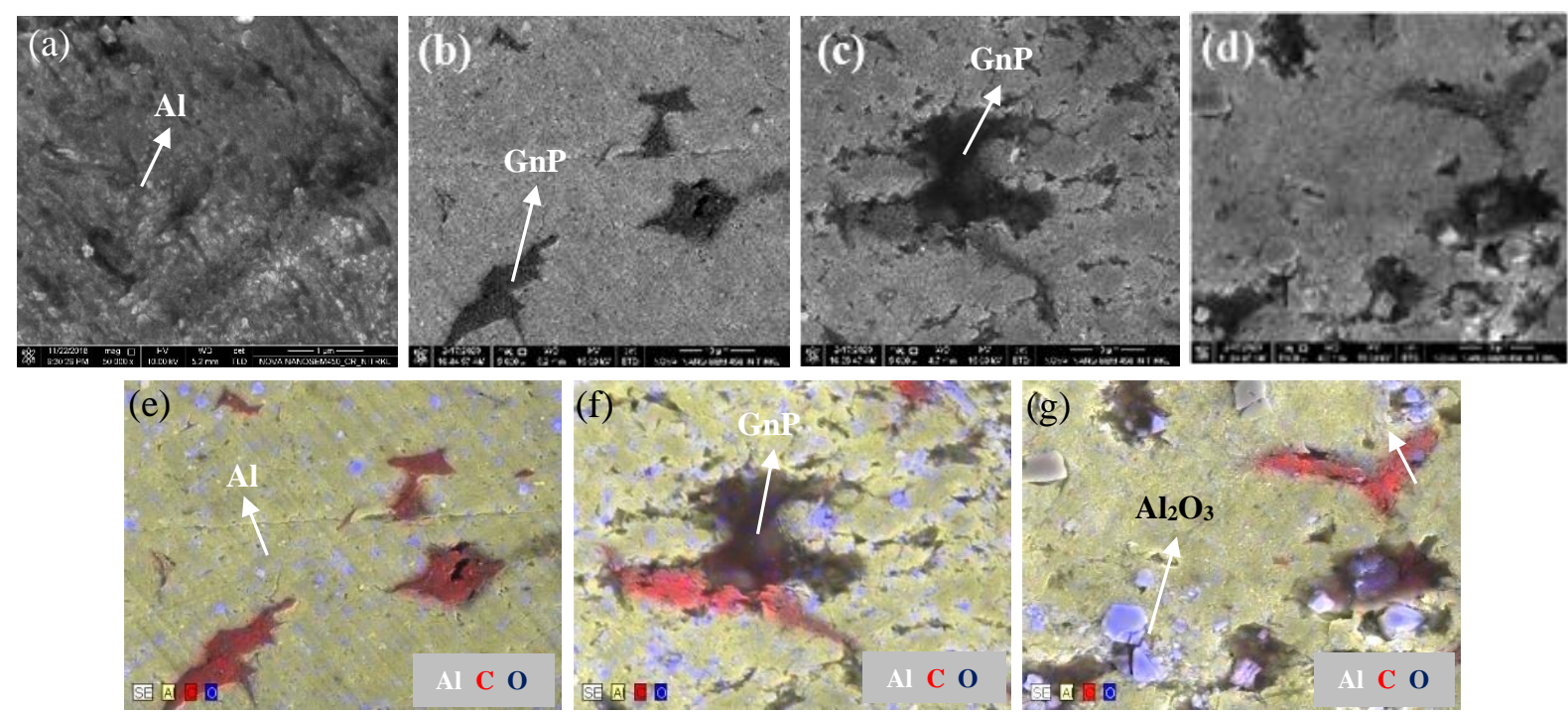

Fig. 12. (A-D) SEM micrographs of SPSed pure $\mathrm{Al}$ and $\mathrm{Al}-1$ wt. $\%, 3$ wt. $\%$, and 5 wt. $\% \mathrm{GnP}$ nanocomposites, and (E-G) corresponding elemental maps of the nanocomposites. GnP, graphite nanoplatelet; SEM, scanning electron microscopy; SPS, spark plasma sintering. 
SPSed Al-GnP nanocomposites. The dark agglomerates in the micrographs are the agglomerates of GnPs. A large number of micro-sized voids are evident in the conventionally sintered pure $\mathrm{Al}$ sample [Figure 11(A)], due to which the porosity in the sample was found to be $\sim 13.4 \%$. However, the pure Al sample developed by SPS [Figure 12(A)] shows a very dense surface, and the porosity in the sample was found to be $\sim 4.44 \%$. The SEM micrographs of the SPSed Al-GnP nanocomposites suggest a much better $\mathrm{GnP}$ distribution in the $\mathrm{Al}$ matrix, which is the reason why the SPSed samples show much better densification and possess superior mechanical properties. The very short dwell time of $10 \mathrm{~min}$ in the case of SPS and a lower sintering temperature of $500^{\circ} \mathrm{C}$, as compared to $550^{\circ} \mathrm{C}$ during conventional sintering, lead to the formation of finer grains and a much more uniform nanofiller distribution within the $\mathrm{Al}$ matrix.

The HRTEM micrographs of the Al-3 wt.\% GnP nanocomposites fabricated by conventional sintering are shown in Figure 13. It has been suggested by Kwon et al. [46] that when brittle aluminum carbides are formed and are homogeneously dispersed in the nanocomposite, it could enhance the strength of the nanocomposite. Both stoichiometric and nonstoichiometric $\mathrm{Al}_{4} \mathrm{C}_{3}$ are formed due to the high sintering temperature of $550^{\circ} \mathrm{C}$ and the very slow cooling rate of $5^{\circ} \mathrm{C} / \mathrm{min}$ post sintering, which helps in the formation of these carbides. The size of the nanoparticles also depends on the sintering temperature. The smaller the size, the higher will be the resistance to the grain boundary movement and generation of more dislocation. These nanoparticles provide strengthening by acting as barriers to the dislocation motion. Figure 13(A) shows that most of the $\mathrm{Al}_{4} \mathrm{C}_{3}$ nanoparticles are at the grain boundaries where the $\mathrm{GnP}$ is in contact with the Al. Formation of $\mathrm{Al}_{4} \mathrm{C}_{3}$ at the $\mathrm{Al}-\mathrm{GnP}$ interface is detrimental to the properties of the nanocomposites as the former hampers the load transfer from the matrix to the nanofiller. $\mathrm{Al}_{4} \mathrm{C}_{3}$ also hampers the bonding of Al with the GnPs. A single nanoparticle could be an epicenter for the generation of many dislocations. These nanoparticles could result in an anchoring effect, whereby the $\mathrm{Al}$ grains are restricted from undergoing interfacial slip, thus enhancing the resistance of $\mathrm{Al}$ grains to deformation [47]. The HRTEM micrograph in Figure 13(B) suggests the coexistence of the $\mathrm{Al}$ and $\mathrm{GnP}$ phases. Figure 13(D) is the SAED pattern showing the presence of both the nanocomposite constituents. The elemental map in Figure 13(E) shows the distribution of the constituent elements in the SEM image in Figure 13(C). The GnP nanofiller can be seen associated and embedded in the $\mathrm{Al}$ metal matrix.

Stoichiometric $\mathrm{Al}_{4} \mathrm{C}_{3}$ forms needle-shaped or rod-shaped precipitates. However, from Figure 14, it can be seen that the nanoparticles formed are either circular or close-to-rectangular shape, which suggests the incomplete formation of the carbide. This happens when the carbonaceous material used as reinforcement partially participates in the reaction with Al. A higher temperature and slow cooling rate are required for complete carbide formation [48, 49]. Figure 14 shows the formation of nonstoichiometric $\mathrm{Al}_{4} \mathrm{C}_{3}$ having traces of oxygen in the form of oxide, which happens when complete carbide formation has not taken place. These nonstoichiometric $\mathrm{Al}_{4} \mathrm{C}_{3}$ particles may result in strengthening of precipitation if formed homogeneously within the $\mathrm{Al}$ metal matrix.

Most of the nonstoichiometric $\mathrm{Al}_{4} \mathrm{C}_{3}$ nanoparticles are formed at the grain boundaries, where $\mathrm{Al}$ is in contact with the GnPs. The nonstoichiometric $\mathrm{Al}_{4} \mathrm{C}_{3}$ particles in Figure 14(A) have a composition of 51.54 at.\% Al, 46.21 at.\% C, and 2.25 at.\% $\mathrm{O}$. On the other hand, the dark spherical particle in Figure 14(B) has a composition of 37.18 at.\% Al, 61.79 at.\% C, and 1.03 at.\% O. The HRTEM micrograph in Figure 15 depicts that the GnP layers are fused in the $\mathrm{Al}$ matrix [50]. Orowan strengthening is a significant strengthening mechanism in these nanocomposites, which is due to the passing of dislocations through the closely spaced nanoparticles., Dispersoid strengthening and precipitation strengthening are governed through Orowan dislocation bypassing or by dislocation shearing mechanisms. Thus, the hardening of the nanocomposites is due to the homogeneous dispersion of the $\mathrm{GnPs}$ in the Al matrix and the effective filling of the nanovoids by the GnP nanofiller, which lead to very high densification when the GnP load- 

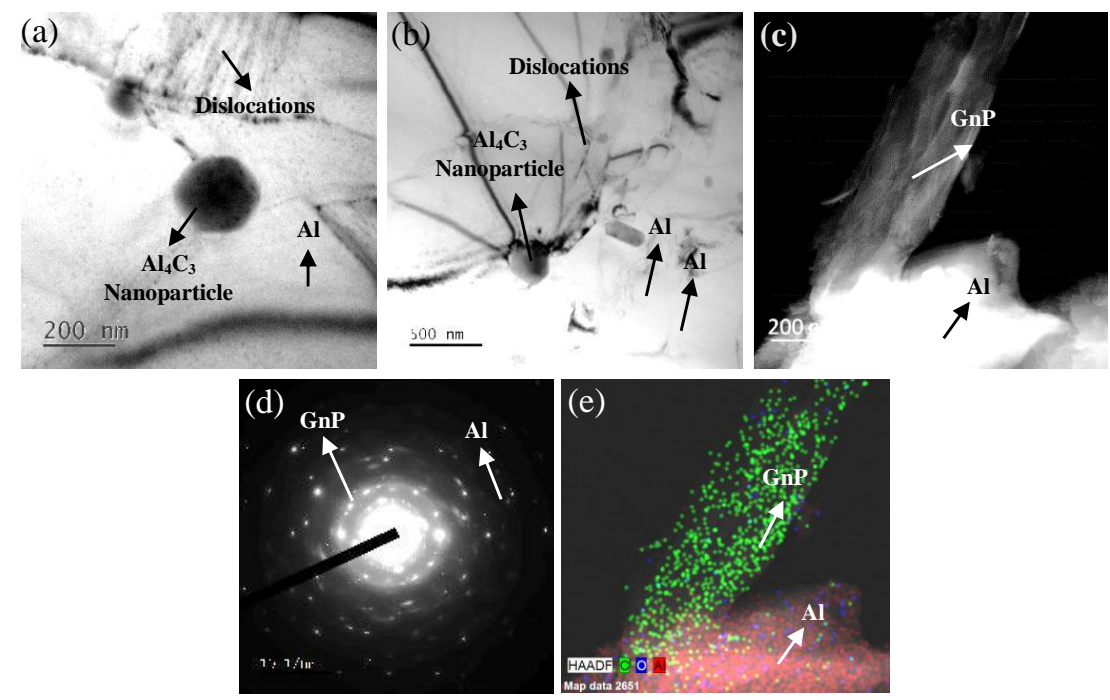

Fig. 13. (A-C) HRTEM micrographs and (D) SAED pattern of conventionally sintered Al-3 wt.\% GnP nanocomposite. (E) Elemental mapping of HRTEM image in panel (C). GnP, graphite nanoplatelet; HRTEM, high-resolution transmission electron microscopy.
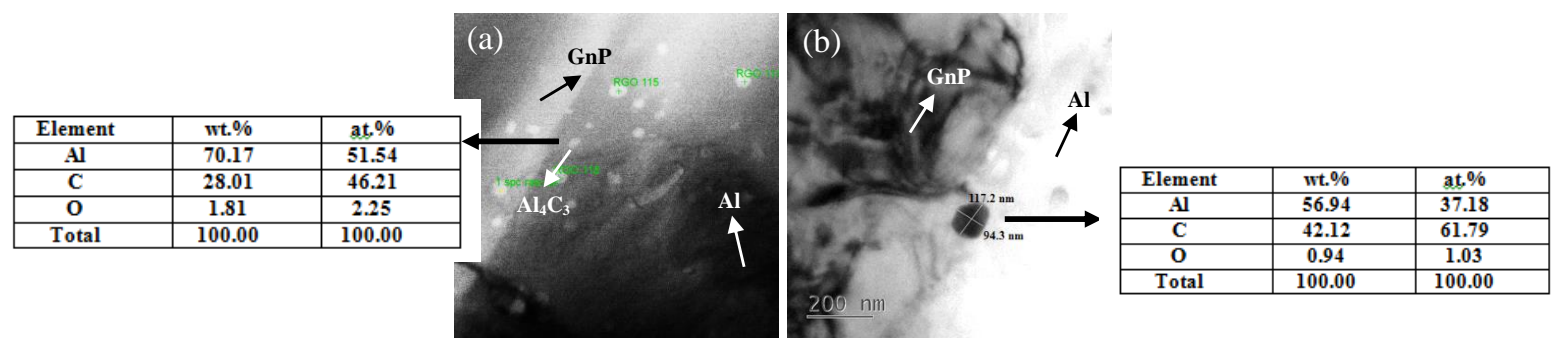

Fig. 14. HRTEM and EDX analysis of $\mathrm{Al}_{4} \mathrm{C}_{3}$ nanoparticles in 3 wt.\% GnP-added conventionally sintered $\mathrm{Al}$ nanocomposite. EDX, energy-dispersive X-ray spectroscopy; GnP, graphite nanoplatelet; HRTEM, highresolution transmission electron microscopy.

ing level is $<3$ wt.\%, thereby leading to a finer grain structure of the matrix. Grain refinement is also a major reason for the strengthening of the nanocomposites [51, 52]. GnPs are capable of restricting the movement of dislocations, and the latter form a loop-like configuration around the GnPs when they cross the GnPs in the slip plane, thereby enhancing the strength of the nanocomposite. Due to the difference between the thermal expansion coefficients of $\mathrm{GnPs}$ and $\mathrm{Al}$, the dislocation density is enhanced, which causes nanocomposite strengthening. As per the Hall-Petch relationship, grain refinement can also lead to significant strength improvement. Nanofillers, when distributed homogeneously in the metal matrix, can lead to grain refinement in the nanocomposites, which significantly improves the nanocomposite's properties [53, 54]. The HRTEM micrographs in Figure 15(C) clearly show GnPs embedded in the Al matrix, and their crystalline structure is well preserved. The SAED patterns shown in the inset in Figure 15(A and B), taken from different regions of the SPSed Al-3 wt.\% GnP nanocomposite sample, suggest the nanocrystalline nature of the sample. This implies that the SPS technique is highly suitable to develop Al-GnP nanocomposites and does not harm the crystal structure of the GnP nanofiller. Figure 15(D) shows dislocation gliding in the $\mathrm{Al}$ grains. 

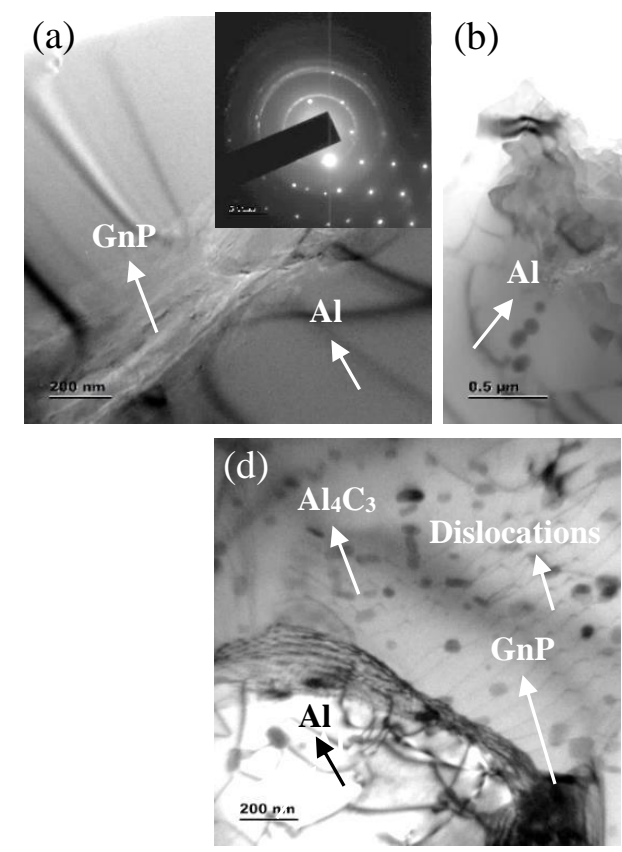

(b)

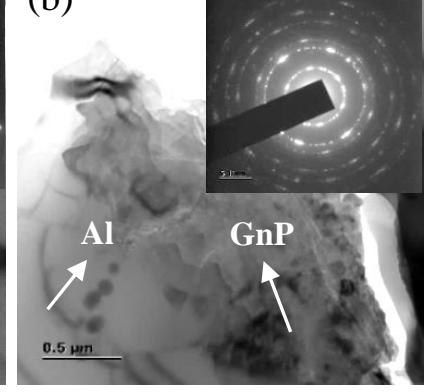

(e)
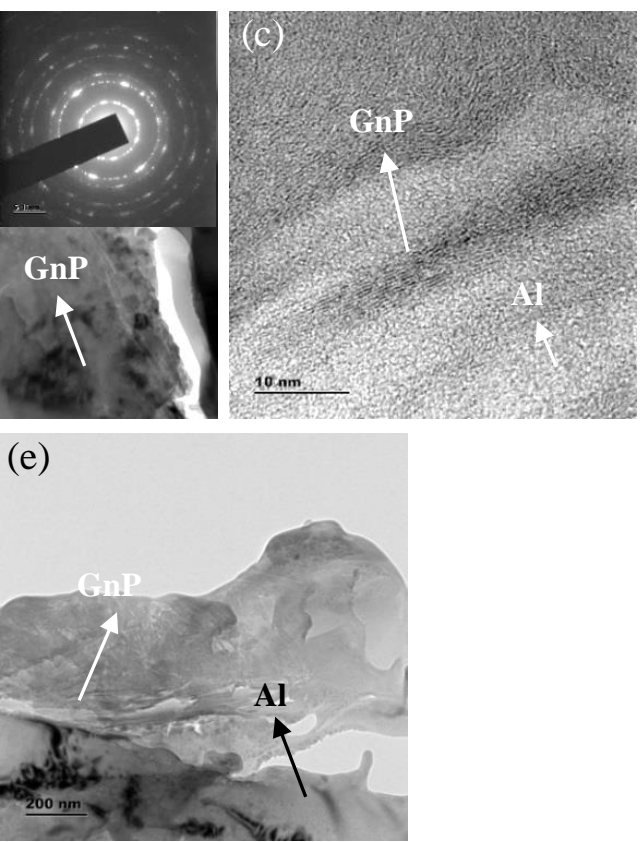

Fig. 15. HRTEM micrographs of SPSed Al-3 wt.\% GnP nanocomposite. GnP, graphite nanoplatelet; HRTEM, high-resolution transmission electron microscopy; SPS, spark plasma sintering.
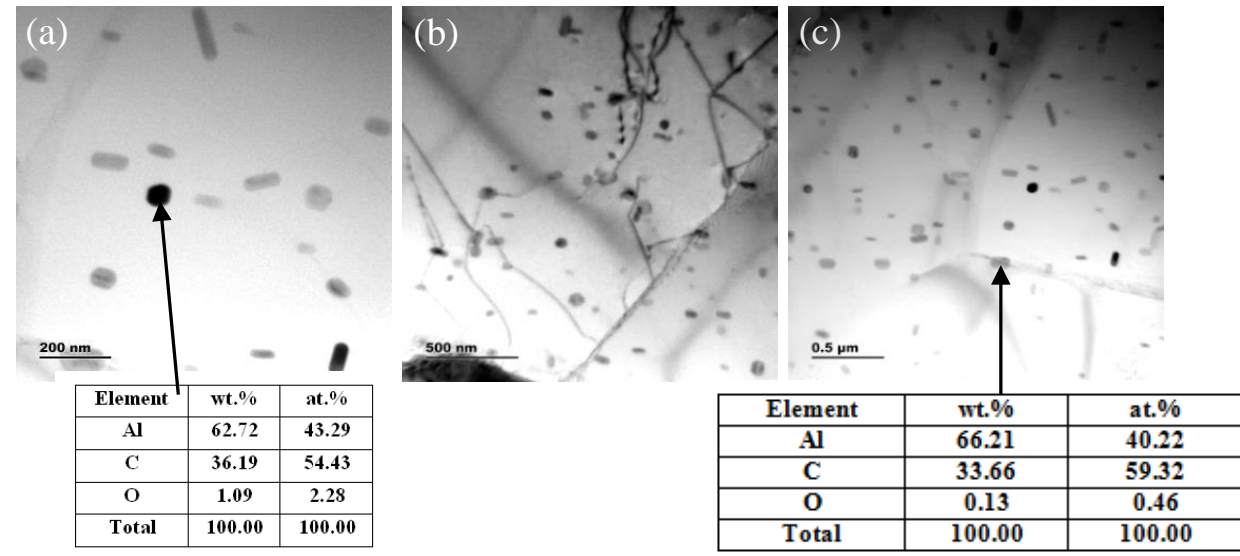

Fig. 16. HRTEM of SPSed Al-3 wt.\% GnP nanocomposite with EDX analysis of $\mathrm{Al}_{4} \mathrm{C}_{3}$ particles. EDX, energydispersive X-ray spectroscopy; GnPs, graphite nanoplatelets; HRTEM, high-resolution transmission electron microscopy; SPS, spark plasma sintering.

When $\mathrm{Al}$ is reinforced with carbon allotropes, such as graphene, CNTs, and so on, it becomes very difficult to limit the formation of the intermetallic compound aluminum carbide $\left(\mathrm{Al}_{4} \mathrm{C}_{3}\right)$. It is seen that whenever the processing temperature exceeds $500^{\circ} \mathrm{C}$, the formation of $\mathrm{Al}_{4} \mathrm{C}_{3}$ occurs. Nonstoichiometric aluminum carbide $\left(\mathrm{Al}_{2} \mathrm{C}\right.$ or $\left.\mathrm{Al}_{2} \mathrm{C}_{2}\right)$, which causes less harm to the mechanical proper- ties, can also form in the $\mathrm{Al}$ matrix due to the reaction with the carbon in the GnPs. These are referred to as undesirable phases in the $\mathrm{Al}-\mathrm{GnP}$ nanocomposites, as these brittle precipitates are hydrophilic and initiate cracks by absorbing moisture. The formation of these carbides is favored when there are more defects in the GnP-free layers, which react with $\mathrm{Al}$ during the sintering process when the 


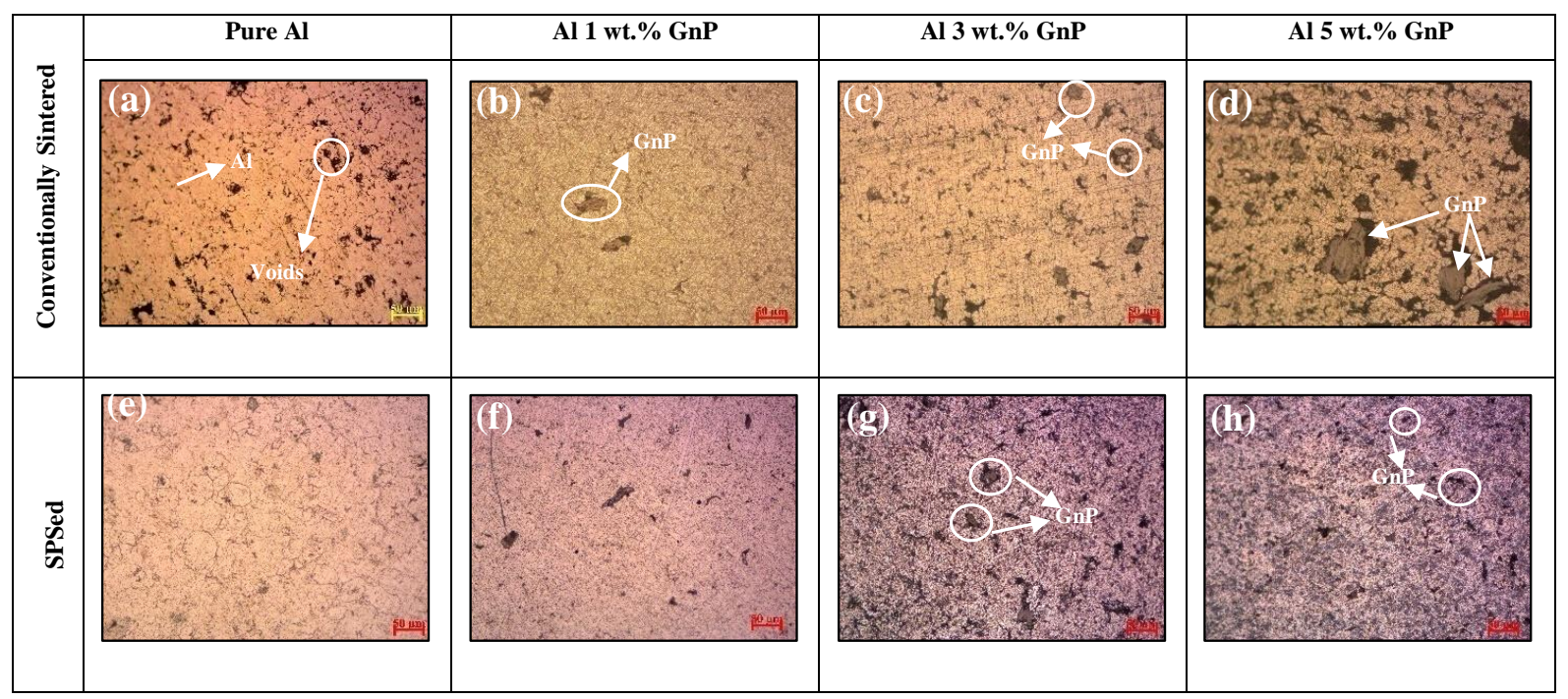

Fig. 17. Optical micrographs of (A-D) conventionally sintered and (B) SPSed samples. GnP, graphite nanoplatelet; SPS, spark plasma sintering.

melting of $\mathrm{Al}$ is initiated. The XRD plots in Figure 10(A) also show the presence of a detectable amount of the carbides in the SPSed nanocomposites. An increment in the reinforcement amount and a higher sintering temperature strongly favor the formation of $\mathrm{Al}_{4} \mathrm{C}_{3}[55,56]$. Figure 16(A and B) shows the presence of dislocations and a large number of near-circular or rectangular-shaped precipitates of nonstoichiometric aluminum carbide over the surface of the Al. At some grain boundaries, clustering of the dislocations can be seen, which results in strengthening of the grain boundary. A grain boundary triple junction, wherein the boundaries of the grains meet at a point and generate a point defect that could initiate a fracture during mechanical application, is considered a defect. Figure 16(C) shows the formation of the triple junction. A triple junction forms in almost every polycrystalline material. Dislocations can be seen being generated in precipitates and grain boundaries, which further get deviated from other precipitates. The nanoparticles help in increasing the strength of the composites by providing resistance to the flow of the dislocations, thus causing local dislocation pile-ups. Strengthening is better when the nanoparticles formed due to the slow cooling post sintering are homogeneously dispersed in the
Al matrix [17, 57]. Dislocation strengthening, precipitation hardening, and formation of fine grains are the major mechanisms that provide strengthening to the SPSed Al-GnP nanocomposites. Energydispersive X-ray spectroscopy (EDX) analysis related to the HRTEM micrograph depicted in Figure 17(A) shows the composition of $\mathrm{Al}_{4} \mathrm{C}_{3}$ particles, which is around 42.39 at.\% $\mathrm{Al}, 54.43$ at.\% C, and 2.28 at.\% $\mathrm{O}$, and the EDX analysis along with the HRTEM image in Figure 17(C) also shows a similar composition of 40.22 at.\% $\mathrm{Al}, 59.32$ at.\% $\mathrm{C}$, and 0.46 at.\% $\mathrm{O}$ for the $\mathrm{Al}_{4} \mathrm{C}_{3}$ particles. The composition and shape together suggest the nonstoichiometric nature of the aluminum carbide.

Figure 17 depicts the optical micrographs of conventionally sintered and SPSed Al-GnP nanocomposites. Figure 18(A and B) show the presence of (i) voids in conventionally sintered $\mathrm{Al}$ sample and (ii) micro-sized voids or no voids in the SPSed Al sample. SPS yields grains of reduced size due to lower sintering times. For conventionally sintered nanocomposites with 5 wt.\% nanofiller addition [Figure 17(D)], presence of larger $\mathrm{GnP}$ agglomerates is evident in the $\mathrm{Al}$ matrix. Nanofiller agglomeration in the $\mathrm{Al}$ metal matrix weakens the matrix-reinforcement bond, which leads to deterioration of the wear and me- 

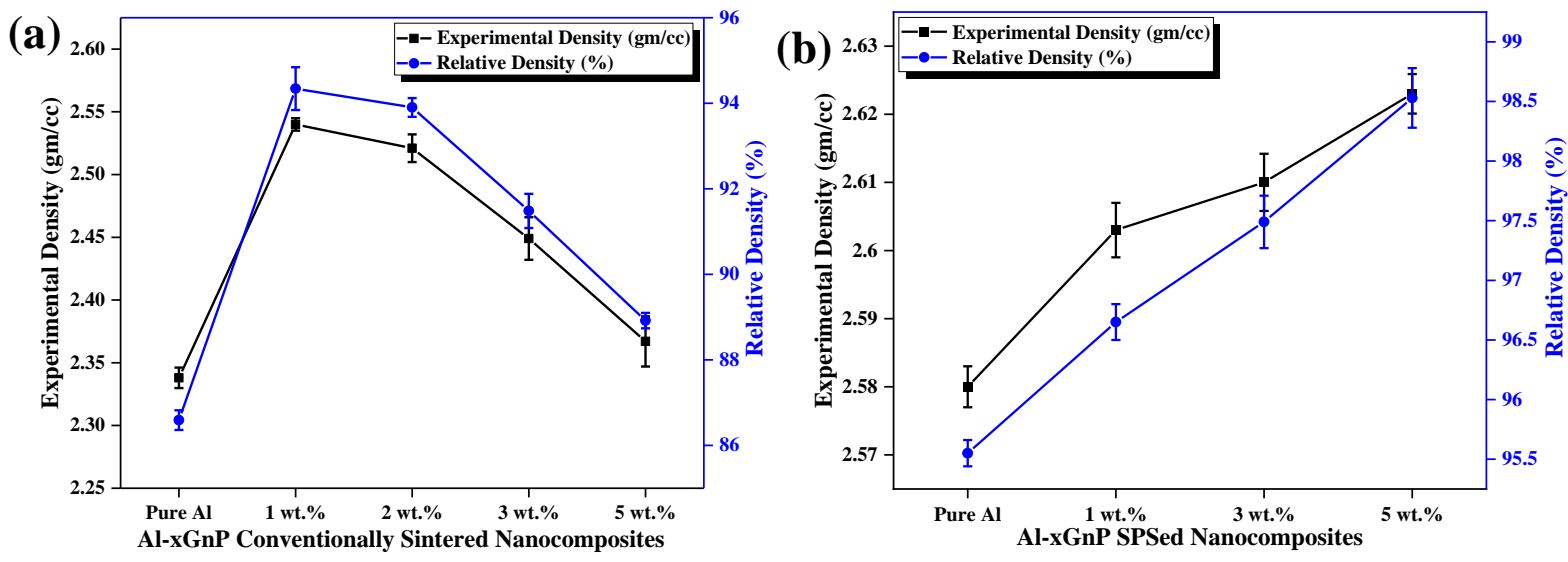

Fig. 18. Experimental and relative densities of (A) conventionally sintered and (B) SPSed samples. GnP, graphite nanoplatelet; SPS, spark plasma sintering.

chanical performance properties of the nanocomposites. The lowest porosity of $\sim 5.65 \%$ was obtained for conventionally sintered $\mathrm{Al} 1 \mathrm{wt} . \% \mathrm{GnP}$ nanocomposite and $\sim 1.47 \%$ for SPSed Al-5 wt.\% $\mathrm{GnP}$ nanocomposite. Comparatively larger voids with lower globularity are significantly more prevalent in the coarse-grained material. The increase in the agglomeration in conventionally sintered nanocomposites is attributed to the increase in the $\mathrm{GnP}$ nanofiller in the $\mathrm{Al}$ matrix. In contrast, for the SPSed Al-GnP nanocomposites, a homogeneous nanofiller dispersion can be seen, which results in a tremendous increase in the mechanical properties [58].

Figure 18 shows the experimental and relative densities of the conventionally sintered and SPSed nanocomposites. It is evident from Figure 18(A) that, compared to pure $\mathrm{Al}$, all the nanocomposites show higher density. The voids in the nanocomposites are filled up by the nanofiller, thus increasing the density of the nanocomposite. However, in the case of conventionally sintered nanocomposites, it can be seen that the nanocomposites show a decrease in the density on addition of GnPs beyond $1 \mathrm{wt} . \%$, due to the agglomeration of the GnPs at the grain boundaries when present beyond the uniform dispersing limit. On the other hand, the SPSed fabricated nanocomposites show a continuous linear increase in the relative density. This shows that the GnP sits in the voids such that the pores are reduced and thus the density is increased. However, with an increase in the loading level of the nanofiller, there is an increase in the agglomeration of the nanofiller in the $\mathrm{Al}$ matrix, which reduces the density of the nanocomposites on addition of GnPs beyond 1 wt.\%. GnPs and Al have very similar densities, and therefore, the addition of GnPs has very little effect on the theoretical density of the nanocomposites as compared to that of Al. On the other hand, SPSed nanocomposites exhibit better densification because, while sintering, grain growth occurs, due to which grain boundary diffusion takes place. This phenomenon shrinks the nanocomposites, which enhances densification. The SPSed nanocomposites show much better densification of the composites than conventionally sintered nanocomposites. Rapid heating is achieved by applying an electric current across the green compact. Pressure-applied SPS significantly reduces the sintering temperature as compared to pressureless sintering. SPS minimizes grain growth and the ability to retain a fine-grained microstructure. Figure 17 also indicates a much more homogeneous $\mathrm{GnP}$ distribution in the $\mathrm{Al}$ matrix for SPSed nanocomposites as compared to the distribution for conventionally sintered nanocomposites $[59,60]$. The highest density of $\sim 94.34 \%$ and $\sim 98.53 \%$ was obtained for conventionally sintered Al-1 wt.\% GnP nanocomposite and SPSed Al-5 wt.\% GnP nanocomposites, respectively. 
(a)

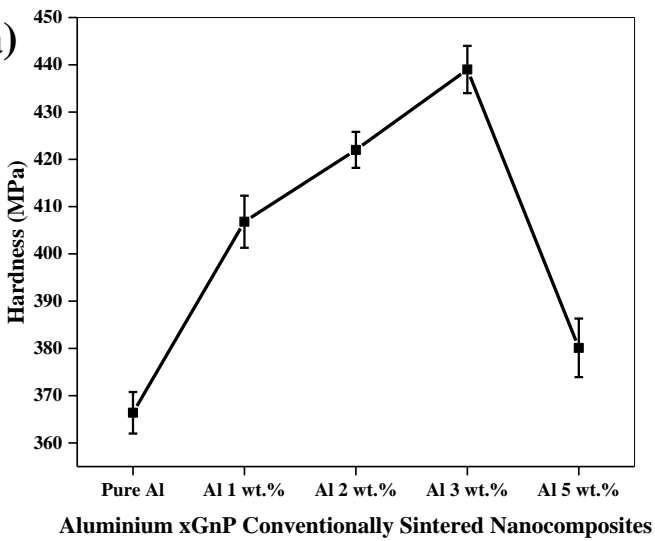

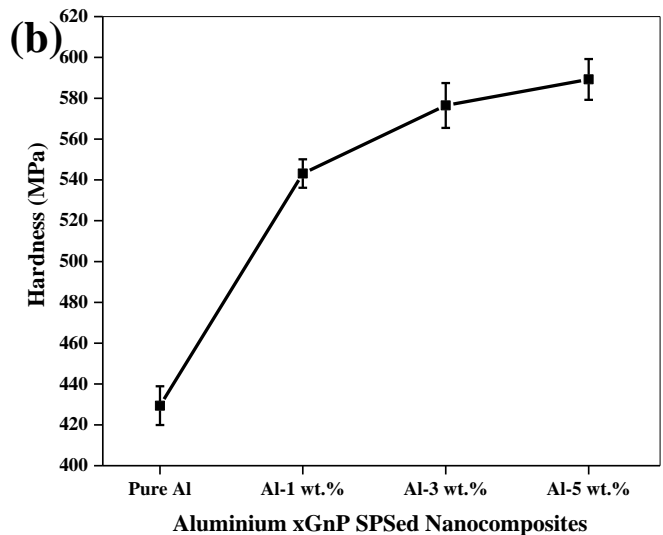

Fig. 19. Variation of hardness in (A) conventionally sintered and (B) SPSed samples. GnP, graphite nanoplatelet; SPS, spark plasma sintering.

Figure 19(A and B) show the microhardness plot of Al-GnP nanocomposites fabricated by conventional sintering and SPS. GnP nanofiller addition was found to be significantly effective in enhancing the hardness of the nanocomposites. From the graphs, it is clear that the GnP nanofiller addition significantly increases the hardness of both conventionally sintered and SPSed nanocomposites as compared to similarly developed pure $\mathrm{Al}$ samples. The hardness imparted by the GnPs is due to the high crystallinity and strength of GnPs, these properites thus enhancing the overall strength of the bulk nanocomposites. Dispersion strengthening is one of the major factors behind the enhancement of hardness of the $\mathrm{Al}-\mathrm{GnP}$ nanocomposites. SPS can result in a fine-grained microstructure with minimum grain growth. The refinement in the grain size and the uniform distribution of $\mathrm{GnP}$ together inhibit the motion of dislocations, which - in turn -helps in increasing the hardness. The sharp decrease in the hardness value for conventionally sintered $\mathrm{Al}-5$ wt.\% GnP nanocomposite could be due to the higher reinforcement agglomeration throughout the Al matrix, which deteriorates the mechanical properties of the nanocomposite. The maximum hardness of $439 \mathrm{MPa}$ was obtained for conventionally sintered Al-3 wt.\% GnP nanocomposite, which is $20 \%$ higher as compared to pure $\mathrm{Al}$ (366.4 MPa). On the other hand, the maximum hardness of $\sim 590 \mathrm{MPa}$ was obtained for the SPSed Al-5 wt.\% GnP nanocomposite, which is $37.5 \%$ higher than the hardness of SPSed pure $\mathrm{Al}$ and $64.4 \%$ higher than the hardness of conventionally sintered $\mathrm{Al}-5$ wt.\% GnP nanocomposite [61, 62].

The plot in Figure 20(A) depicts the variation in wear depth versus time behavior, whereas Figure 20(B) depicts the calculation of the wear rate and mass loss with respect to the reinforcement content for conventionally sintered pure $\mathrm{Al}$ and the various $\mathrm{Al}-\mathrm{GnP}$ nanocomposites. It can be noticed from Figure 20(A) that the pure $\mathrm{Al}$ sample shows the highest wear depth. In other words, it has the lowest wear resistance. The wear depth continuously increases with time. It should also be noted that pure Al [Figure 19(A)] also shows the lowest hardness as compared to all the other Al-GnP nanocomposites. From Figure 20(A), it is understood that the wear depth of various nanocomposites follows the same nature as the variation of their hardness [Figure 19(A)], i.e., Al-3 wt.\% $\mathrm{GnP}$ nanocomposites having the highest hardness also show the lowest wear depth along with the lowest wear rate. The wear resistance of the Al-5 wt.\% GnP conventionally sintered nanocomposite is found to be the lowest among all the Al-GnP nanocomposites. The reason could be the presence of high nanofiller agglomeration when added beyond $3 \mathrm{wt} \%$. However, the wear behavior of the Al-5 wt.\% GnP nanocomposite is found to be better 

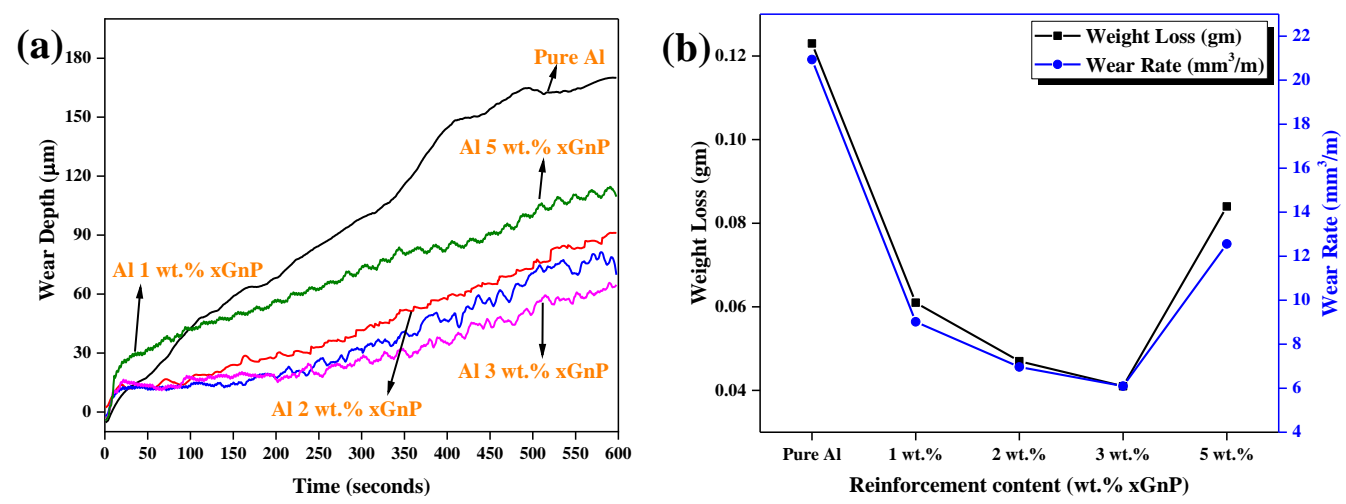

Fig. 20. Variation in (A) wear depth and (B) wear rate of conventionally sintered samples.
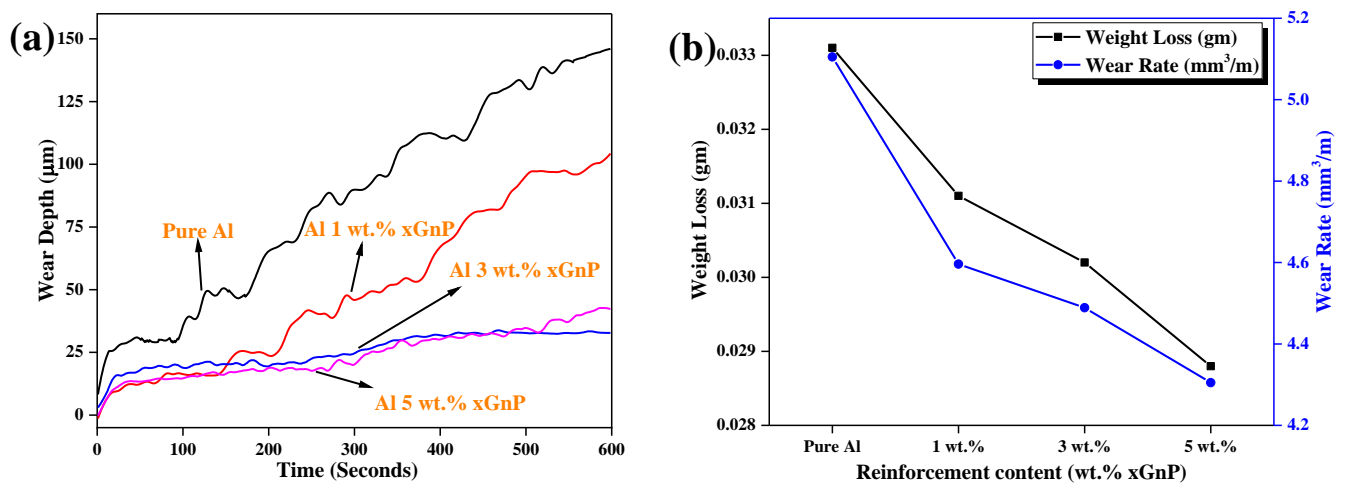

Fig. 21. Variation in (A) wear depth and (B) wear rate of SPSed samples. GnP, graphite nanoplatelet; SPS, spark plasma sintering.

than that of pure Al. It should also be noted that Al5 wt.\% GnP nanocomposite also has slightly higher hardness as compared to that of pure Al. The trend in the variation of the wear rate [Figure 20(B)] is also very similar to the trend in the variation of hardness [Figure 19(A)] and wear depth [Figure 21(A)]. Conventionally sintered pure $\mathrm{Al}$ shows the poorest wear behavior, and $\mathrm{Al} \mathrm{3-wt. \%} \mathrm{GnP}$ nanocomposite shows the best wear characteristic. The wear rate of $\mathrm{Al}-5 \mathrm{wt} . \% \mathrm{GnP}$ nanocomposite shows a slight increase as compared to that of Al-3 wt.\% GnP. Therefore, from the results of the wear test, it can be concluded that 3 wt.\% GnP addition is the optimum loading level giving the best wear resistance properties. For both conventional sintering and SPS, pure Al exhibits the poorest wear characteristic, i.e., highest wear depth, wear rate, and wear loss. A continuous increase in the wear depth of pure $\mathrm{Al}$ and the various $\mathrm{Al}-\mathrm{GnP}$ nanocom- posites suggests nonuniformity in sintering, which is attributed to the high heating rate during sintering. The variation in the grain size from the center to the outer periphery of the sample increases remarkably due to nonuniform sintering. Nonuniform sintering behavior leads to nonuniform densification of the sample with depth, leading to a difference in the wear behavior and hardness with the depth of the sample. On the other hand, uniform sintering results in uniformity in properties such as hardness and wear resistance throughout the depth of the sample. The formation of a nonuniform microstructure is intuitive to the adopted sintering conditions, such as rate of heating, pressure applied during sintering, dwell time, thermal gradient, and so on [63]. The increase in wear characteristics of the synthesized $\mathrm{Al}-\mathrm{GnP}$ nanocomposites can be credited to the formation of the GnP sacrificial layer between the ball and the nanocompos- 


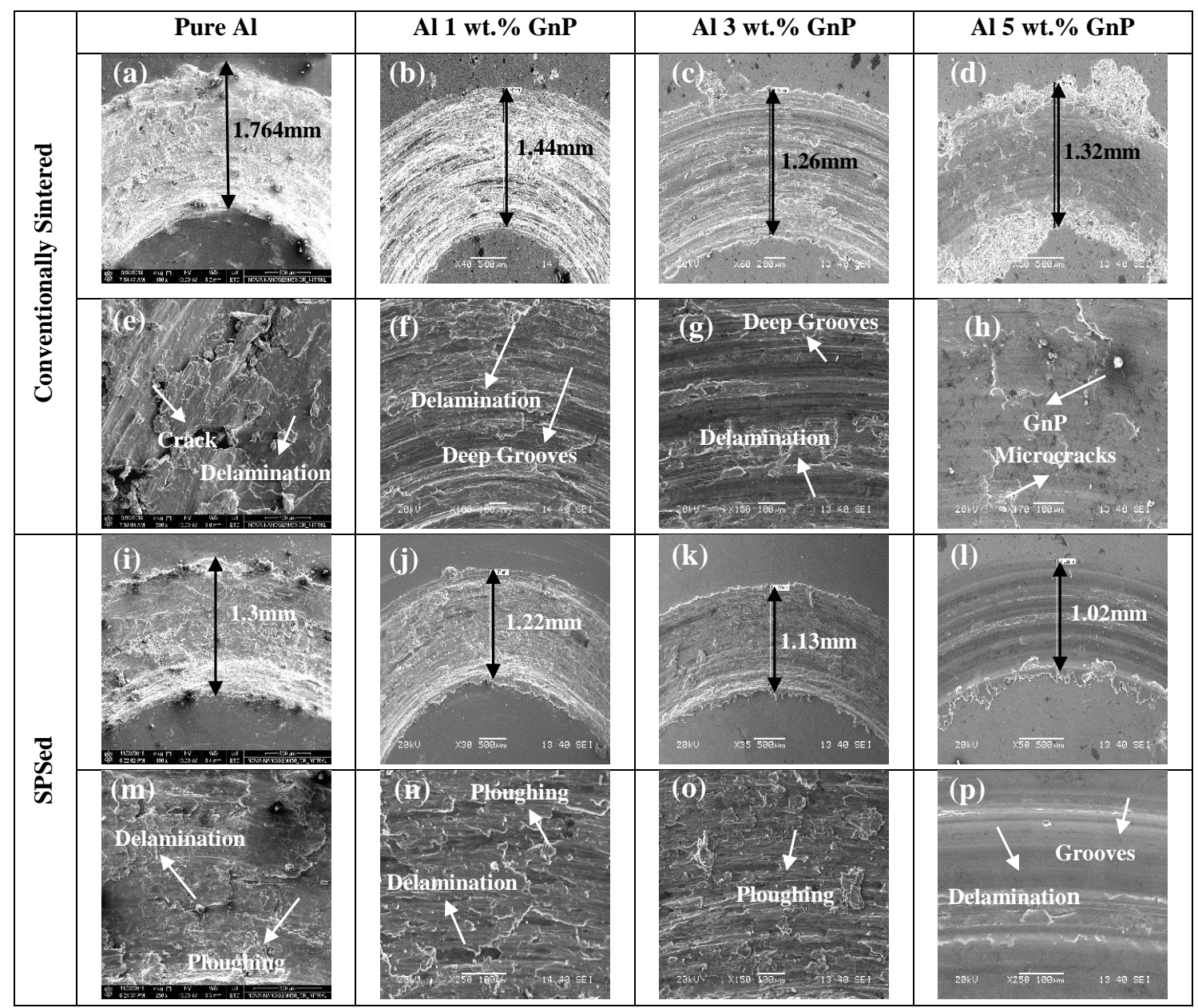

Fig. 22. SEM micrographs of the wear tracks of conventionally sintered and SPSed samples. GnP, graphite nanoplatelet; SEM, scanning electron microscopy; SPS, spark plasma sintering.

ite, which reduces the contact area by giving rise to a smooth surface and thus decreasing the wear depth. This decrease in wear loss is also due to the strengthening of the nanocomposites by the addition of GnPs.

Figure 21(A) depicts the variation of wear depth with time, and Figure 21(B) shows the variation of wear rate for SPS-fabricated pure $\mathrm{Al}$ and the various $\mathrm{Al}-\mathrm{GnP}$ nanocomposites. It is known that $\mathrm{GnP}$ has friction-reducing potential and can decrease the friction forces that act during wear on the surfaces at the micro and nano levels. It can be seen from Figure 21(A and B) that with the increase in the loading level of the GnPs, a decrease in both the wear depth and wear rate is observed. GnPs, due to their high specific surface area, can very efficiently and homogeneously disperse in the matrix when added as the second phase and fill the voids, forming a protective tribolayer that reduces the friction coefficient. The wear depth goes on increasing with an increase in sliding time for both pure $\mathrm{Al}$ and Al-1 wt.\% GnP nanocomposite. However, for Al3 wt. $\%$ and 5 wt. $\%$ GnPs, the wear depth was maintained constant with increase in sliding time due to the uniform sintering of the nanocomposites. The wear rate decreases with increasing loading level of GnPs due to the formation of a better protective layer of GnPs at the wear surface and the lubricating effect of the GnPs. The lowest wear depth and the lowest wear rate and wear depth for the SPSed nanocomposite are observed for Al-5 wt.\% GnP nanocomposite [64, 65]. 

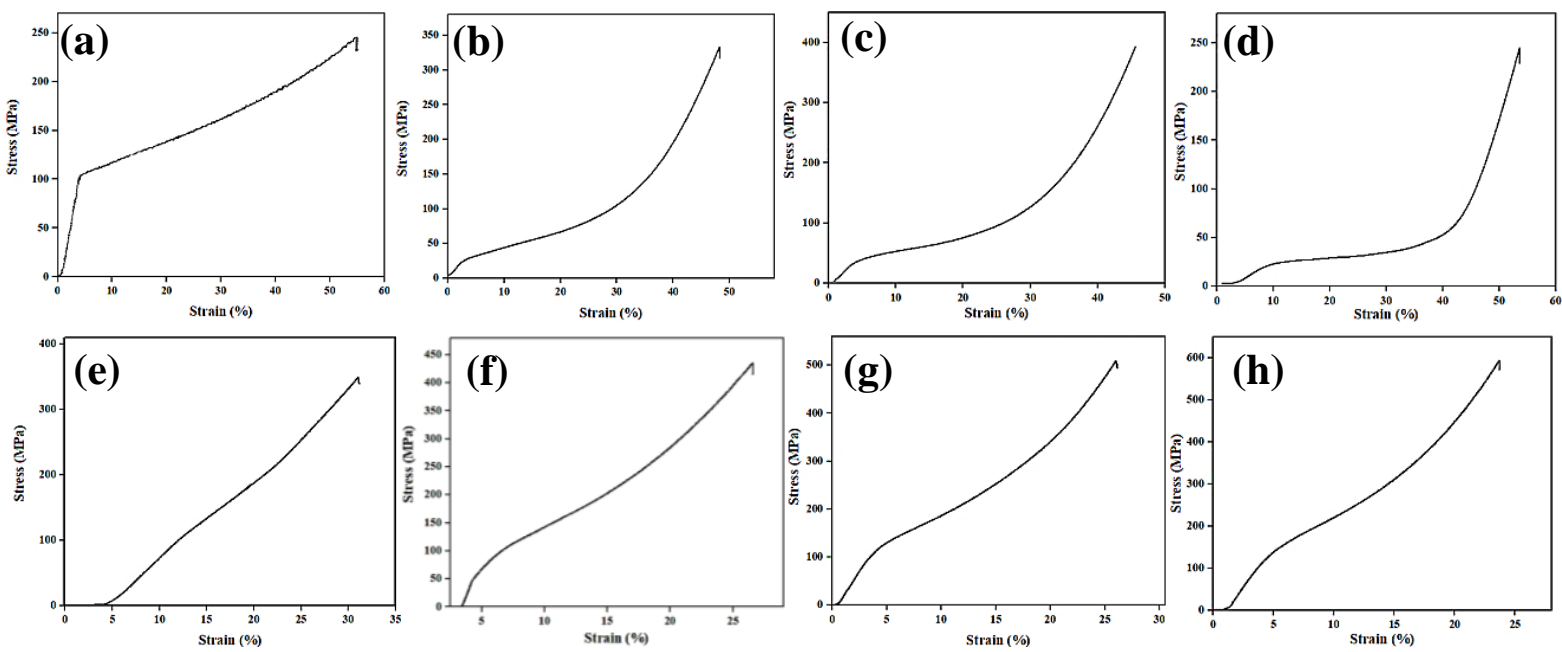

Fig. 23. Compressive $\sigma-\varepsilon$ curves of pure $\mathrm{Al}, \mathrm{Al}-1 \mathrm{wt} . \%, 3$ wt. $\%$, and 5 wt. $\% \mathrm{GnP}$ reinforced (A-D) conventionally sintered and (E-H) SPSed samples. GnP, graphite nanoplatelet; SPS, spark plasma sintering.

Figure 22 depicts the SEM micrographs of the worn surfaces of pure $\mathrm{Al}$ and $\mathrm{Al}-\mathrm{GnP}$ nanocomposites. The SEM images show plowing, grooving, delamination, and cracks. Microcracks and porosity lead to weakening of the mechanical and wear properties of the nanocomposite [66, 67]. Hardness inhibits the tearing off of particles from the surface due to which smooth grooves form on the wear track. The wear track of conventionally sintered $\mathrm{Al}$, shown in Figure 22(A and E), shows pores or voids caused by the pull-out of grains, delamination, and a large number of cracks. In the case of conventionally sintered nanocomposites, the largest wear track width of $1.764 \mathrm{~mm}$ was observed for pure $\mathrm{Al}$ and the smallest wear track width of $1.26 \mathrm{~mm}$ was observed with Al-3 wt.\% GnP nanocomposite. The wear track SEM micrographs of the conventionally sintered Al-3 wt.\% GnP in Figure 22(C and $\mathrm{G}$ ) were found to be very smooth grooves with very little wear debris in the wear track. Parallel grooves have appeared on the wear surfaces of all the nanocomposites. For conventionally sintered Al-5 wt.\% GnP nanocomposite, microcracks could be seen on the surface due to the sudden increase in the wear rate after the initial period of wear test. Among the conventionally sintered nanocomposites, Al-3 wt.\% GnP nanocomposite shows the best wear properties. A better wear characteristic was observed with SPSed Al-GnP nanocompos- ites compared to conventionally sintered nanocomposites. The SEM micrographs of the wear track of SPSed Al-5 wt.\% GnP nanocomposite in Figure 22( $\mathrm{L}$ and $\mathrm{P}$ ) show smooth grooving and very few delaminations, due to uniform and high densification. Very little wear debris is seen in the wear track. The pull-out of grains at the contact surface, along with very few cracks, is seen in the wear track. Nanocomposites developed by SPS show a much smaller width of the wear tracks, and this width continuously reduces with increase in the GnP nanofiller content. In the case of SPSed nanocomposites, the largest wear track width of $1.3 \mathrm{~mm}$ was observed for pure $\mathrm{Al}$ and the smallest wear track width of $1.02 \mathrm{~mm}$ was observed with Al-5 wt.\% GnP nanocomposite [68, 69].

Compression tests are effective in the determination of the modulus values of nanocomposites as they are independent of both grain size and the impurity level in the samples. Figure 23 depicts the compression curves of the Al-GnP nanocomposites fabricated by conventional sintering and SPS. For the conventionally sintered nanocomposites, the compression curves show that both the modulus and compressive strength significantly increase up to $3 \mathrm{wt}$ \% GnP nanofiller addition, which is attributed to the dispersion strengthening provided by the GnP nanofiller. Due to better densification, the nanocomposites developed by SPS show higher 
(a)

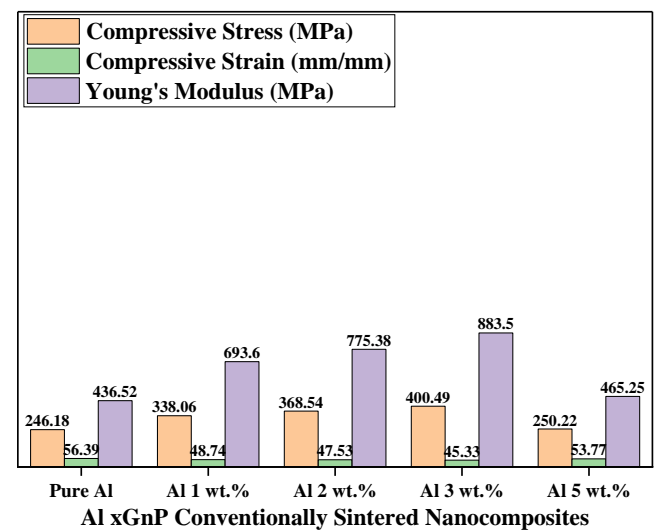

(b)

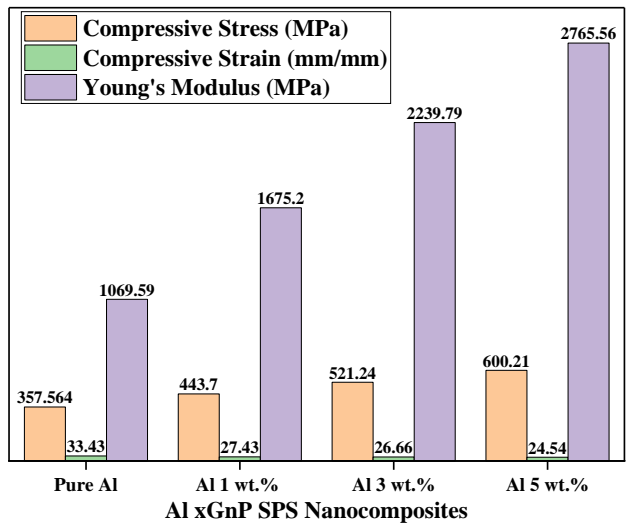

Fig. 24. Compressive strength, strain, and elastic modulus of various (A) conventionally sintered and (B) SPSed samples. GnP, graphite nanoplatelet; SPS, spark plasma sintering.

modulus and compressive strength [70]. The nature of the curves is similar for all the nanocomposites, and all the nanocomposites failed by brittle failure. The plots in Figure 24 indicate that the nanocomposites exhibit brittle characteristics when the loading level of the nanofiller is increased, as the strain to failure of the nanocomposites is reduced. The compressive strength and the modulus of the SPSed nanocomposites increase monotonously with an increase in the $\mathrm{GnP}$ addition upto $5 \mathrm{wt}$.\%. The nanosized $\mathrm{GnP}$ obstructs the dislocation movements and thus strengthens the nanocomposites. It is evident from Figure 24(A) that for conventionally sintered nanocomposites, there is an increase in the modulus and compressive strength on addition of up to 3 wt.\% GnP into the $\mathrm{Al}$ matrix. However, for Al-5 wt.\% GnP nanocomposite, nonuniform dispersion and agglomeration of the GnP nanofiller result in the reduction of both the compressive stress and the modulus. Uniform GnP dispersion results in higher strength values. However, with the increase in $\mathrm{GnP}$ content beyond 3 wt.\%, higher nanofiller agglomeration takes place in the $\mathrm{Al}$ matrix, leading to the deterioration of its mechanical properties. There is an increase in compressive stress of $62 \%$ for the conventionally sintered $\mathrm{Al}-3 \mathrm{wt} . \%$ GnP nanocomposite and $67.8 \%$ for the SPSed Al5 wt.\% GnP nanocomposite, when compared with that for pure $\mathrm{Al}$, fabricated under similar conditions. Furthermore, there is a decrease in the strain to failure of $\sim 19.6 \%$ for conventionally sintered
Al-3 wt.\% GnP nanocomposite and $~ 26.6 \%$ for SPSed Al-5 wt.\% GnP nanocomposite, indicating an increase in the brittle nature of the nanocomposite with an increase in the loading level of GnPs in the nanocomposites. The highest elastic modulus of $\sim 883.5 \mathrm{MPa}$ was observed for conventionally sintered Al-3 wt.\% GnP nanocomposite and $\sim 2.7 \mathrm{GPa}$ for the SPSed Al-5 wt.\% GnP nanocomposite [71, 72].

\section{Conclusions}

This study aims to find out the effect of GnP addition on the microstructure and various mechanical properties of Al-GnP nanocomposites developed by the PM route. It is observed that there is an optimum amount of reinforcement addition for enhancement of any individual property. Precipitation hardening, grain refinement, and dislocation strengthening are the major reasons for the enhanced mechanical properties of the nanocomposites. The following are the conclusions drawn from the study.

1. Compared to sintered pure $\mathrm{Al}$ sample, there is an $\sim 8.2 \%$ increase in density for conventionally sintered nanocomposite in the case of Al-1 wt.\% GnP nanocomposite and $\sim 3.02 \%$ increase for SPSed Al-5 wt.\% $\mathrm{GnP}$ nanocomposite. An increase in the $\mathrm{GnP}$ loading level in conventionally sintered nanocomposites leads to agglomera- 
tion of GnPs in the Al matrix, which increases the voids and decreases the density. A finer grain structure and homogeneous nanofiller distribution are the reasons behind the linear increase in density of SPSed nanocomposites. The highest relative density among the conventionally sintered nanocomposites was $\sim 94.34 \%$ for the Al-1 wt.\% GnP nanocomposite. However, the highest relative density for the SPSed nanocomposites was $\sim 98.53 \%$ for the Al5 wt.\% GnP nanocomposite.

2. The hardness values of the conventionally sintered Al-GnP nanocomposites showed a significant increase upto $3 \mathrm{wt} \%$ of nanofiller addition, and beyond that level, the property deteriorates due to nanofiller agglomeration. Moreover, 20\% increase in hardness was observed in the case of Al3 wt.\% GnP nanocomposite $(\sim 439 \mathrm{MPa})$ with respect to pure $\mathrm{Al}$ (366.4 MPa). Precipitation hardening, Orowan strengthening, grain refinement, and dislocation strengthening are the major reasons for the enhanced mechanical properties of the SPSed nanocomposites. The maximum hardness in the case of SPSed Al-GnP nanocomposite was found to be $\sim 590 \mathrm{MPa}$ in the case of $\mathrm{Al}-5$ wt. $\% \mathrm{GnPs}$, which is $~ 37.5 \%$ higher than the hardness of the pure $\mathrm{Al}(\sim$ 429.4 MPa) sample sintered under similar conditions.

3. In the case of conventional sintering, a significant reduction in wear rate and wear depth was achieved due to the addition of GnPs only up to a critical mass fraction of 3 wt.\% of GnPs owing to the agglomeration of GnPs at higher concentrations. $\mathrm{GnP}$ is a well-known self-lubricating nanofiller that prevents direct contact between the contact surfaces by providing a film of lubrication. Deterioration in wear properties was observed at a higher concentration of GnPs due to the congregation of $\mathrm{GnP}$ clusters in the $\mathrm{Al}$ matrix. However, in the case of the SPSed nanocomposites, there is a continu- ous increase in the wear properties of the nanocomposites up to the addition of $5 \mathrm{wt} . \%$ of GnPs owing to the finer grain structure and enhanced density of the samples.

4. The compressive $\sigma-\varepsilon$ curves obtained for the various nanocomposites showed a similar trend. The modulus and compressive strength of the conventionally sintered nanocomposites showed a good increase in their values as compared to those of pure Al. An enhancement in the strength of $\sim$ $62 \%$ and decrease in the strain to failure of $\sim 19.6 \%$ were observed for conventionally sintered Al-3 wt.\% GnP nanocomposite with respect to pure Al. However, for the Al-5 wt.\% GnP nanocomposite, both the compressive strength and the modulus showed a decrease due to the agglomeration and nonuniform dispersion of GnPs. However, for the SPSed nanocomposites, there is a continuous increase in the strength upto $\sim 67.8 \%$ and $\mathrm{a} \sim 26.6 \%$ decrease in the strain to failure in the case of the Al-5 wt.\% $\mathrm{GnP}$ nanocomposite as compared to pure $\mathrm{Al}$ owing to the finer grain structure, which results in higher surface area and higher dislocation density, which enhance the strength of the nanocomposite.

\section{Acknowledgements}

The authors would like to acknowledge the support provided by the Central Research Facility (CRF), National Institute of Technology (NIT) Rourkela, for allowing us to analyze our samples using techniques such as HRTEM, SEM, and FESEM. The authors would also like to appreciate and acknowledge the help and support provided by Indian Institute of Technology (IIT) Kanpurthe, for helping us in sintering our samples using the SPS technique, procured with partial funding from CARE funding, the Department of Science and Technology (DST), Government of India. We are also immensely grateful to PSG College of Technology, Coimbatore, for providing us with the HRTEM facility, which was fully funded by the PSG College of Technology Institute of Advanced Studies (PSGIAS).

\section{Conflict of Interest}

The authors declare that they have no conflicts of interest. 


\section{References}

[1] Kumar HP, Xavior MA. Graphene reinforced metal matrix composite (GRMMC): A review. Procedia Eng. 2014;97:1033-40. https://doi.org/10.1016/j.proeng.201 4.12.381

[2] Miracle DB. Metal matrix composites - From science to technological significance. Compos Sci Technol. 2005;65:2526-2540. https://doi.org/10.1016/j.compscit ech.2005.05.027

[3] Moghadam AD, Schultz BF, Ferguson JB, Omrani E, Rohatgi PK, Gupta N. Functional metal matrix composites: Self-lubricating, self-healing, and nanocomposites-An Outlook. JOM. 2014;66:872-81. https://doi.org/10.1007/s11837-014-0948-5

[4] Moghadam AD, Omrani E, Menezes PL, Rohatgi PK. Mechanical and tribological properties of self-lubricating metal matrix nanocomposites reinforced by carbon nanotubes (CNTs) and graphene - A review. Compos Part B. 2015;77:402-20. https://doi.org/10.1016/j.compositesb.2015.03.014

[5] Shin SE, Choi HJ, Shin JH, Bae DH. Strengthening behavior of few-layered graphene/aluminum composites. Carbon. 2015;82:143-51. https://doi.org/10.1016/ j.carbon.2014.10.044

[6] Bisht A, Srivastava M, Kumar RM, Lahiri I, Lahiri D. Strengthening mechanism in graphene nanoplatelets reinforced aluminum composite fabricated through spark plasma sintering. Mater Sci Eng. 2017;695:20-8. https://doi.org/10.1016/j.msea.2017.04.009

[7] Georgakilas V, Perman JA, Tucek J, Zboril R. Broad family of carbon nanoallotropes: Classification, chemistry, and applications of fullerenes, carbon dots, nanotubes, graphene, nanodiamonds, and combined superstructures. Chem Rev. 2015;115:4744-822. https://doi.org/10.1021/cr500304f

[8] Dixit S, Mahata A, Mahapatra DR, Kailas SV, Chattopadhyay K. Multi-layer graphene reinforced aluminum - Manufacturing of high strength composite by friction stir alloying. Compos Part B. 2018;136:63-71. https://doi.org/10.1016/j.compositesb.2017.10.028

[9] Saboori A, Novara C, Pavese M, Badini C, Giorgis $\mathrm{F}$, Fino $\mathrm{P}$, An investigation on the sinterability and the compaction behavior of aluminum/graphene nanoplatelets (GNPs) prepared by powder metallurgy. J Mater Eng Perform. 2017;26:993-9. https://doi.org/ $10.1007 / \mathrm{s} 11665-017-2522-0$

[10] Shrivastava P, Alam SN, Panda D, Sahoo SK, Maity T, Biswas K. Effect of addition of multiwalled carbon nanotube/graphite nanoplatelets hybrid on the mechanical properties of aluminium. Diam Relat Mater. 2020;104:107715. https://doi.org/10.1016/ j.diamond.2020.107715

[11] Rashad M, Pan F, Tang A, Asif M. Effect of graphene nanoplatelets addition on mechanical properties of pure aluminum using a semi-powder method. Prog Nat Sci Mater Int. 2014;24:101-108. https://doi.org/10.1016/j.pnsc.2014.03.012
[12] Yolshina LA, Muradymov RV, Vichuzhanin DI, Smirnova EO. Enhancement of the mechanical properties of aluminum-graphene composites. AIP Conference Proc. 2016;1785:040093. https://doi.org/10. 1063/1.4967150

[13] Baradeswaran A, Perumal AE. Wear and mechanical characteristics of Al 7075/graphite composites. Compos Part B. 2014;56:472-6. https://doi.org/10. 1016/j.compositesb.2013.08.073

[14] Kurşun A, Bayraktar E, Enginsoy HM. Experimental and numerical study of alumina reinforced aluminum matrix composites: Processing, microstructural aspects and properties. Compos Part B. 2016;90:302-14. https://doi.org/10.1016/j.compositesb.2016.01.006

[15] Bastwros M, Kim GY, Zhu C, Zhang K, Wang S, Tang $\mathrm{X}$, et al. Effect of ball milling on graphene reinforced Al6061 composite fabricated by semisolid sintering. Compos Part B. 2014;60:111-8. https://doi.org/10.1016/j.compositesb.2013.12.043

[16] Shrivastava P, Alam SN, Panda D, Sahoo SK, Maity T, Biswas K. Development and mechanical properties investigation of $\mathrm{Cu}$-MWCNT-graphite nanoplatelets hybrid nanocomposites. Diam Relat Mater. 2021;117:108467. https://doi.org/10.1016/j.diamond.2 021.108467

[17] Boostani AF, Yazdani S, Mousavian RT, Taham$\tan$ S, Khosroshahi RA, Wei D, et al. Strengthening mechanisms of graphene sheets in aluminium matrix nanocomposites. Mater Des. 2015;88:983-9. https://doi.org/10.1007/s12633-019-00183-9

[18] Dasari BL, Nouri JM, Brabazon D, Naher S. Graphene and derivatives - Synthesis techniques, properties and their energy applications. Energy. 2017;140:766-78. https://doi.org/10.1016/j.energy.2017.08.048

[19] Bartolucci SF, Paras J, Rafiee MA, Rafiee J, Lee S, Kapoor D, et al. Graphene-aluminum nanocomposites. Mater Sci Eng A. 2011;528:7933-7. https://doi.org/10. 1016/j.msea.2011.07.043

[20] Ju JM, Wang G, Sim KH. Facile synthesis of graphene reinforced Al matrix composites with improved dispersion of graphene and enhanced mechanical properties. J Alloys Compd. 2017;704:585-92. https://doi.org/10.1016/j.jallcom.2017.01.314

[21] Dutkiewicz J, Ozga P, Maziarz W, Pstruś J, Kania $\mathrm{B}$, Bobrowski $\mathrm{P}$, et al. Microstructure and properties of bulk copper matrix composites strengthened with various kinds of graphene nanoplatelets. Mater Sci Eng A. 2015;628:124-34. https://doi.org/10.1016/j.msea.2015.01.018

[22] Chang YH, Huang D, Jia C, Cui Z, Wang C, Liang D. Influence of plasma on the densification mechanism of SPS under multi-field effect. Int J Miner Metall Mater. 2014;21:906-12. https://doi.org/10.1007/s12613-0140988-4

[23] Nie JH, Jia CC, Shi N, Zhang Y, Li Y, Jia X. Aluminum matrix composites reinforced by molybdenumcoated carbon nanotubes. Int $\mathbf{J}$ Miner Metall Mater. 
2011;18:695-702. https://doi.org/10.1007/s12613-0110499-5

[24] Dimiev AM, Shukhina K, Behabtu N, Pasquali M, Tour JM. Stage transitions in graphite intercalation compounds: Role of the graphite structure. J Phys Chem C. 2019;123:19246-53. https://doi.org/10.1021/acs.jpcc.9b06726

[25] Walker P, editors. Handbook of Metal Etchants. 1st ed. New York: CRC Press; 2019.

[26] Naeem M, Kuan HC, Michelmore A, Yu S, Mouritz AP, Chelliah SS, et al. Epoxy/graphene nanocomposites prepared by in-situ microwaving. Carbon. 2021;177:27181. https://doi.org/10.1016/j.carbon.2021.02.059

[27] Drzal LT, Fukushima H. Exfoliated graphite nanoplatelets (xGnP): A carbon nanotube alternative. NSTI Nanotech. 2006;1:170-3.

[28] Stobinski L, Lesiak B, Malolepszy A, Mazurkiewicz M, Mierzwa B, Zemek J, et al. Graphene oxide and reduced graphene oxide studied by the XRD, TEM and electron spectroscopy methods. J Electron Spectros Relat Phenomena. 2014;195:145-54. https://doi.org/10.1016/j.elspec.2014.07.003

[29] Chen G, Weng W, Wu D, Wu C, Lu J, Wang P, et al. Preparation and characterization of graphite nanosheets from ultrasonic powdering technique. Carbon. 2004;42:753-9. https://doi.org/10.1016/j.carbon. 2003.12.074

[30] Afanasov IM, Shornikova ON, Kirilenko DA, Vlasov II, Zhang L, Verbeeck J, et al. Graphite structural transformations during intercalation by HNO3 and exfoliation. Carbon. 2010;48:1862-5. https://doi.org/10.1016/S1872-5805(11)60085-1

[31] Dutta A. Fourier transform infrared spectroscopy. In: Spectroscopy Methods Nanomater Character. Elsevier;2017. pp. 73-93.

[32] Stankovich S, Dikin DA, Piner RD, Kohlhaas KA, Kleinhammes A, Jia Y, et al. Synthesis of graphenebased nanosheets via chemical reduction of exfoliated graphite oxide. Carbon. 2007;45:1558-65. https://doi.org/10.1016/j.carbon.2007.02.034

[33] Sinha S, Warner JH. Recent progress in using graphene as an ultrathin transparent support for transmission electron microscopy. Small Struct. 2021;2:2000049. https://doi.org/10.1002/sstr.202000049

[34] Ferrari AC, Robertson J. Interpretation of Raman spectra of disordered and amorphous carbon. Phys Rev B. 2000;61:14095-07. https://doi.org/10.1103/PhysRev B.61.14095

[35] Ferrari AC, Basko DM. Raman spectroscopy as a versatile tool for studying the properties of graphene. Nat Nanotechnol. 2013;8:235-246. https://doi.org/10. 1038/nnano.2013.46

[36] Yang G, Li L, Lee WB, Ng MC. Structure of graphene and its disorders: A review. Sci Technol Adv Mater. 2018;19:613-48. https://doi.org/10.1080/ 14686996.2018.1494493

[37] Wang G, Yang J, Park J, Gou X, Wang B, Liu
$\mathrm{H}$, et al. Facile synthesis and characterization of graphene nanosheets. J Phys Chem C. 2008;112:819295. https://doi.org/10.1021/jp710931h

[38] Tian WM, Li SM, Wang B, Chen X, Liu JH, Yu M. Graphene-reinforced aluminum matrix composites prepared by spark plasma sintering. Int J Miner Metall Mater. 2016;23:723-9. https://doi.org/10.1007/s12613016-1286-0

[39] Manoratne CH, Rosa SR, Kottegoda IR. XRD-HTA, UV visible, FTIR and SEM interpretation of reduced graphene oxide synthesized from high purity vein graphite. Mater Sci Res India. 2017;14:19-0. https://doi.org/10.13005/msri/140104

[40] Thema FT, Moloto MJ, Dikio ED, Nyangiwe NN, Kotsedi L, Maaza M, et al. Syntehies and characterization of graphene thin films by chemical reduction of exfoliated and intercalated graphite oxide. J Chem. 2013;1:1-6. https://doi.org/10.1155/2013/150536

[41] Jeyasimman D, Sivaprasad K, Sivasankaran S, Narayanasamy R. Fabrication and consolidation behavior of Al 6061 nanocomposite powders reinforced by multi-walled carbon nanotubes. Powder Technol. 2014;258:189-7. https://doi.org/10.1016/j.pow tec.2014.03.039

[42] Kuzumaki T, Miyazawa K, Ichinose H, Ito K. Processing of carbon nanotube reinforced aluminum composite. J Mater Res. 1998;13:2445-49. https://doi.org/10. 1557/JMR.1998.0340

[43] Heping L, Fenger S, Yibo G, Shaolei C, Xingbin J. Preparation of graphene coated aluminum composite powders by high-energy ball milling. IOP Conf Ser Mater Sci Eng. 2019;544:012043. https://doi.org/10.1088/1757-899X/544/1/012043

[44] Kumar SN, Keshavamurthy R, Haseebuddin MR, Koppad PG. Mechanical properties of aluminium-graphene composite synthesized by powder metallurgy and hot extrusion. Trans Indian Inst Met. 2017;70:605-13. https://doi.org/10.1007/s12666-017-1070-5

[45] Wang J, Guo LN, Lin WM, Chen J, Liu CL, Zhang $\mathrm{S}$, et al. Effect of the graphene content on the microstructures and properties of graphene/aluminum composites. New Carbon Mater. 2019;34:275-85. https://doi.org/10.1016/s1872-5805(19)60016-8

[46] Kwon H, Park DH, Silvain JF, Kawasaki A. Investigation of carbon nanotube reinforced aluminum matrix composite materials. Compos Sci Technol. 2010;70:546-50. https://doi.org/10.1016/j.compscitech. 2009.11.025

[47] Zhou W, Yamaguchi T, Kikuchi K, Nomura N, Kawasaki A. Effectively enhanced load transfer by interfacial reactions in multi-walled carbon nanotube reinforced Al matrix composites. Acta Mater. 2017;125:369-76. https://doi.org/10.1016/j.actamat.2016.12.022

[48] Etter T, Schulz P, Weber M, Metz J, Wimmler M, Löffler JF, et al. Aluminium carbide formation in interpenetrating graphite/aluminium composites. Mater Sci Eng A. 2007;448:1-6. https://doi.org/10. 
1016/j.msea.2006.11.088

[49] Kurita H, Kwon H, Estili M, Kawasaki A. Multi-walled carbon nanotube-aluminum matrix composites prepared by combination of heteroagglomeration method, spark plasma sintering and hot extrusion. Mater Trans. 2011;52:1960-65. https://doi.org/10.2320/matertrans.M2011146

[50] Chen B, Shen J, Ye X, Imai H, Umeda J, Takahashi $\mathrm{M}$, et al. Solid-state interfacial reaction and load transfer efficiency in carbon nanotubes (CNTs)-reinforced aluminum matrix composites. Carbon. 2017;114:198-8. https://doi.org/10.1016/j.carbon.2016.12.013

[51] Zhang Z, Chen DL. Consideration of Orowan strengthening effect in particulate-reinforced metal matrix nanocomposites: A model for predicting their yield strength. Scr Mater. 2006;54:1321-6. https://doi.org/10.1016/j.scriptamat.2005.12.017

[52] Ma K, Wen H, Hu T, Topping TD, Isheim D, Seidman DN, et al. Mechanical behavior and strengthening mechanisms in ultrafine grain precipitationstrengthened aluminum alloy. Acta Mater. 2014;62:1415. https://doi.org/10.1016/j.actamat.2013.09.042

[53] Ovid'ko IA, Sheinerman AG. Nanoparticles as dislocation sources in nanocomposites. J Phys Condens Matter. 2006;18:L225-2. https://doi.org/10.1088/09538984/18/19/L01

[54] Vo NQ, Sorensen J, Klier EM, Zadeh AS, Bayansan D, Seidman DN, et al. Development of a precipitationstrengthened matrix for non-quenchable aluminum metal matrix composites. JOM. 2016;68:1915-24. https://doi.org/10.1007/s11837-016-1896-Z

[55] Zhang J, Chen Z, Zhao J, Jiang Z. Microstructure and mechanical properties of aluminiumgraphene composite powders produced by mechanical milling. Mech Adv Mater Mod Process. 2018;4:1-9. https://doi.org/10.1186/s40759-018-0037-5

[56] Sharifi EM, Enayati MH, Karimzadeh F. Fabrication and characterization of $\mathrm{Al}-\mathrm{Al} 4 \mathrm{C} 3$ nanocomposite by mechanical alloying. Int $\mathrm{J}$ Mod Phys Conf Ser. 2012;05:480-7. https://doi.org/10.1142/ S2010194512002371

[57] Azarniya A, Safavi MS, Sovizi S, Azarniya A, Chen B, Hosseini HM, et al. Metallurgical challenges in carbon nanotube-reinforced metal matrix nanocomposites. Metals (Basel). 2017;7:384. https://doi.org/10.3390/met7100384

[58] Khalili D. Graphene oxide: A promising carbocatalyst for the regioselective thiocyanation of aromatic amines, phenols, anisols and enolizable ketones by hydrogen peroxide/KSCN in water. New J Chem. 2016;40:254753. https://doi.org/10.1039/C5NJ02314A

[59] Anselmi-Tamburini U. Spark plasma sintering. In: Encyclopedia of Materials: Technical Ceramics and Glasses. Elsevier; 2021. pp. 294-310. https://doi.org/10.1016/ B978-0-12-803581-8.11730-8

[60] Omori M. Sintering, consolidation, reaction and crystal growth by the spark plasma system (SPS). Mater Sci
Eng A. 2000;287:183-8. https://doi.org/10.1016/S09215093(00)00773-5

[61] Kwon H, Estili M, Takagi K, Miyazaki T, Kawasaki A. Combination of hot extrusion and spark plasma sintering for producing carbon nanotube reinforced aluminum matrix composites. Carbon. 2009;47:570-7. https://doi.org/10.1016/j.carbon.2008.10.041

[62] Awotunde MA, Adegbenjo AO, Obadele BA, Okoro $\mathrm{M}$, Shongwe BM, Olubambi PA. Influence of sintering methods on the mechanical properties of aluminium nanocomposites reinforced with carbonaceous compounds: A review. J Mater Res Technol. 2019;8:243249. https://doi.org/10.1016/j.jmrt.2019.01.026

[63] Gao X, Yue H, Guo E, Zhang S, Wang B, Guan E, et al. Preparation and tribological properties of homogeneously dispersed graphene-reinforced aluminium matrix composites. Mater Sci Technol. 2018;34:1316-22. https://doi.org/10.1080/02670836.2018.1446869

[64] Lee JH, Kim BN, Jang BK. Non-uniform sintering behavior during spark plasma sintering of $\mathrm{Y}_{2} \mathrm{O}_{3}$. Ceram Int. 2020;46:4030-4. https://doi.org/10.1016/j.ceramint. 2019.10.070

[65] Rohatgi PK, Tabandeh-Khorshid M, Omrani E, Lovell MR, Menezes PL. Tribology of metal matrix composites. In: Tribology Science Engineering. New York: Springer;2013. pp. 233-268. https://doi.org/10.1007/978-1-4614-1945-7_8

[66] Smirnov A, Peretyagin P, Pinargote NWS, Gershman I, Bartolomé JF. Wear behavior of graphene-reinforced alumina-silicon carbide whisker nanocomposite. Nanomaterials. 2019;9:151. https://doi.org/10.3390/ nano9020151

[67] Chih A, Ansón-Casaos A, Puértolas JA. Frictional and mechanical behaviour of graphene/UHMWPE composite coatings. Tribol Int. 2017;116:295-2. https://doi.org/10.1016/j.triboint.2017.07.027

[68] Kumar HGP, Xavior MA. Tribological aspects of graphene-aluminum nanocomposites. In: Kyzas GZ, Mitropoulos AC, editors. Graphene Materials - Structure Properties and Modifications. IntechOpen; 2017. https://doi.org/10.5772/67475

[69] Zhang J, Chen Z, Wu H, Zhao J, Jiang Z. Effect of graphene on the tribolayer of aluminum matrix composite during dry sliding wear. Surf Coatings Technol. 2019;358:907-12. https://doi.org/10.1016/ j.surfcoat.2018.11.065

[70] Nayak B, Sahu RK, Karthikeyan P. Study of tensile and compressive behaviour of the in-house synthesized al-alloy nano composite. IOP Conf Ser Mater Sci Eng. 2018;402:012070. https://doi.org/10.1088/1757899X/402/1/012070

[71] Raj RR, Yoganandh J, Saravanan MS, Kumar SS. Effect of graphene addition on the mechanical characteristics of AA7075 aluminium nanocomposites. Carbon Lett. 2021;31:125-36. https://doi.org/10.1007/s42823020-00157-7

[72] Li JL, Xiong YC, Wang XD, Yan SJ, Yang C, 
He WW, et al. Microstructure and tensile properties of bulk nanostructured aluminum/graphene composites prepared via cryomilling. Mater Sci Eng. 2015;626:400405. https://doi.org/10.1016/j.msea.2014.12.102

Received 2021-07-03 Accepted 2021-10-17 